WSRC-TR-2001-00163

\title{
Degradation and Failure Characteristics of NPP Containment Protective Coating Systems
}

\section{Preliminary Evaluation of Plant Coating Specimens}

\author{
Prepared by
}

M. E. Dupont, N. C. lyer, P. S. Lam, R. L. Sindelar,

T. E. Skidmore, F. R. Utsch and P. E. Zapp

Savannah River Technology Center Westinghouse Savannah River Company

Aiken, SC 29808

\section{For}

Division of Engineering Technology Office of Nuclear Regulatory Research

U.S. Nuclear Regulatory Commission

Washington, DC 20555

NRC Job Code W6959

NRC Project Managers: M. L. Marshall, Jr.

J. R. Boardman

Publication Date: March 2001

Westinghouse Savannah River Company

Savannah River Site

Aiken, SC 29808

This document was prepared in connection with work done under Contract No. DE-AC09-96SR18500 with the U. S. Department of Energy 


\section{DISCLAIMER}

This report was prepared as an account of work sponsored by an agency of the United States Government. Neither the United States Government nor any agency thereof, nor any of their employees, makes any warranty, express or implied, or assumes any legal liability or responsibility for the accuracy, completeness, or usefulness of any information, apparatus, product or process disclosed, or represents that its use would not infringe privately owned rights. Reference herein to any specific commercial product, process or service by trade name, trademark, manufacturer, or otherwise does not necessarily constitute or imply its endorsement, recommendation, or favoring by the United States Government or any agency thereof. The views and opinions of authors expressed herein do not necessarily state or reflect those of the United States Government or any agency thereof.

This report has been reproduced directly from the best available copy.

Available for sale to the public, in paper, from: U.S. Department of Commerce, National Technical Information Service, 5285 Port Royal Road, Springfield, VA 22161

phone: $(800) 553-6847$

fax: (703) 605-6900

email: orders@ntis.fedworld.gov

online ordering: http://www.ntis.gov/ordering.htm

Available electronically at http://www.doe.gov/bridge

Available for a processing fee to U.S. Department of Energy and its contractors, in paper, from: U.S. Department of Energy, Office of Scientific and Technical Information, P.O. Box 62, Oak Ridge, TN 37831-0062

phone: (865) 576-8401

fax: (865) $576-5728$

email: reports@adonis.osti.gov 
DOCUMENT: $\quad$ WSRC-TR-2001-00163

TITLE: Degradation and Failure Characteristics of NPP Containment Protective Coating Systems

\section{APPROVALS}

Mark E. Dupont, Author

Date: $3 / 28 / 01$

Materials Applications \& Process Technology Group

, Materials Technoloav Section

Natraj C. lyer, Authdr and Manager

Date: $3 / 28 / 01$

Materials Technology Section

Poh-Sang Lam, Author

Date: $3 / 28 / 2001$

Materials Applications \& Process Technology Group

Engineering Development Section

Robert L. Sindelar, Author and Manager

Date: $3 / 28 / 2001$

Materials Applications \& Process Technology Group

Materials Technology Section

T. Eric Skidmore, Author

Date: $3 / 29 / 01$

Materials Consultation Group

Materials Technology Section

Ṕhilip El. Zapp, Attrthó

Date: $3 / 28 / 01$

Materials Performance \& Corrosion Technology Group

Materials Technology Section 


\section{Degradation and Failure Characteristics of NPP Containment Protective Coating Systems}

by

R. L. Sindelar

Westinghouse Savannah River Company

Savannah River Site

Aiken, South Carolina 29808

M. E. Dupont

P. E. Zapp

N. C. Iyer

P. S. Lam

T. E. Skidmore

F. R. Utsch

DOE Contract No. DE-AC09-96SR18500

This paper was prepared in connection with work done under the above contract number with the $U$. S. Department of Energy. By acceptance of this paper, the publisher and/or recipient acknowledges the U. S. Government's right to retain a nonexclusive, royalty-free license in and to any copyright covering this paper, along with the right to reproduce and to authorize others to reproduce all or part of the copyrighted paper. 


\section{Executive Summary}

Service-experienced coating specimens from the containment of several nuclear stations ("plant specimens") were sent to the Savannah River Technology Center (SRTC) for evaluation under the program to investigate coating degradation and failure. ${ }^{1}$ These coating specimens included coating chips that had become disbonded during normal plant operation, and intact coating specimens that were sectioned from steel components in the containment. These specimens were evaluated by several characterization techniques to provide structural and chemical information.

The coating specimens were evaluated in both the as-received (service-experienced) condition and following irradiation-aging and simulated DBA-LOCA conditions. The following conclusions can be drawn from the results of the tests and characterizations.

\section{Coating Chip Specimens:}

- The coating chips had failed within the inorganic zinc (IOZ) layer. A non-uniform distribution of the ethyl silicate binder was observed and most likely caused poor adhesion within the IOZ. The failure is attributed to improper application, rather than in-service environmental degradation.

- The coating chips had a topcoat layer and a layer of IOZ. Exposure of the two-layer chip to simulated DBA-LOCA conditions resulted in extreme curling of the initially flat chip. The curling is explained by differential expansion/contraction between the two layers of the chip.

\section{Intact Coating Specimens:}

- The intact coating specimens, sectioned from plates and handrails from two plants, were tested in the as-received condition. The coatings were sound and strongly adhered following exposure to simulated DBA-LOCA conditions. The as-received condition of these materials was 10 to 20 years of normal operation service.

- The intact coating specimens were also tested following irradiation-aging to $10^{9} \mathrm{rad}\left(\right.$ at $10^{6} \mathrm{rad} / \mathrm{hr}$ at $120^{\circ} \mathrm{F}$ ). Severe blistering and the formation of particulate debris were observed when these specimens were exposed to simulated DBA-LOCA conditions. This behavior is similar to that observed in similar, recently-applied coatings on laboratory specimens, albeit the depth of topcoat damage in these plant specimens was greater than the laboratory specimens $(\sim 10$ mils vis-à-vis $\sim 2$ mils $)$.

\footnotetext{
I The NRC commissioned SRTC to investigate the potential for degradation and failure of NPP coating systems due to the concerns raised in NRC generic letter 98-04 dated July 14, 1998. The principle approach in the research program was to evaluate laboratory specimens prepared in accordance with appropriate ASTM standards [ref. WSRC-TR-2001-00067]. The plant specimens were to be evaluated to verify the results and conclusions from the accelerated aging of the laboratory specimens.
} 


\section{Table of Contents}

Page

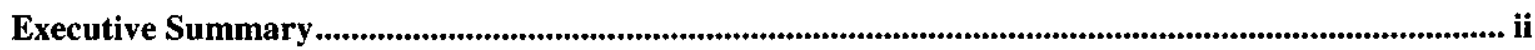

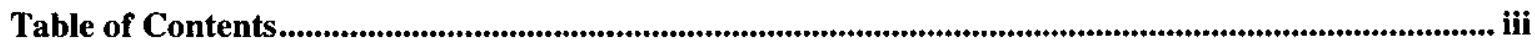

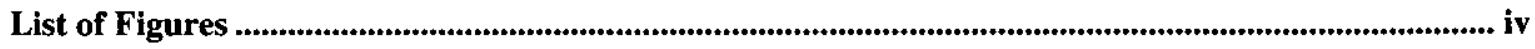

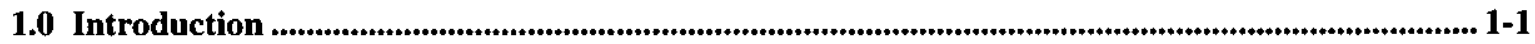

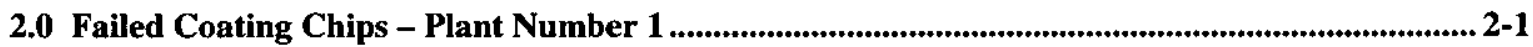

2.1 Debris Characterization - General Observations....................................................... 2-1

2.2 Scanning Electron Microscopy (SEM) Examination................................................ 2-2

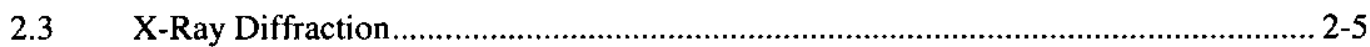

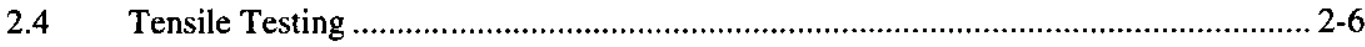

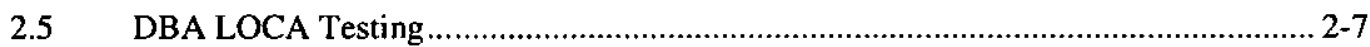

2.6 Analytical Modeling of Two-Layer Coating …........................................................ 2-9

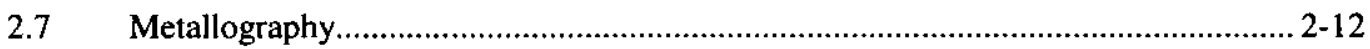

3.0 Failed Coating Chips - Plant Number 2 ......................................................................................... 3-1

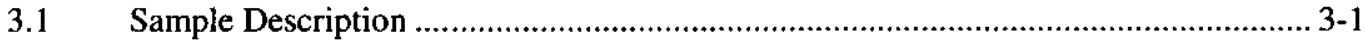

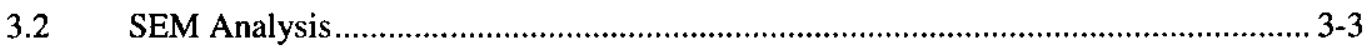

4.1 Plate Specimens - Plant Number 3....................................................................................................... 4-1

4.1.1 D3911 DBA/LOCA - First Test....................................................................... 4-1

4.1.2 D3911 DBA/LOCA - Second Test with partial immersion ........................................ 4-3

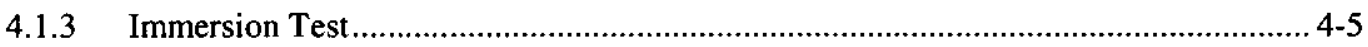

4.1.4 Adhesion Pull Test Results ................................................................................. 4-6

4.2 Handrail Specimen - Plant Number 3 ............................................................................................... 4-8

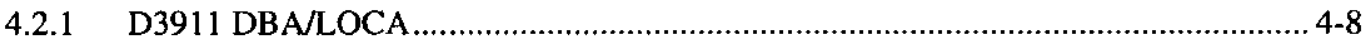

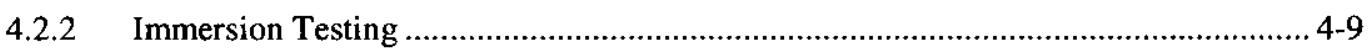

5.0 Contaminated Plate Specimens - Plant Number 4 …....................................................................... 5-1

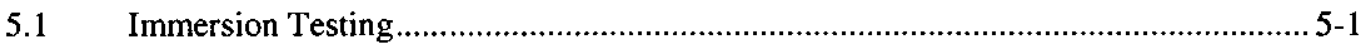

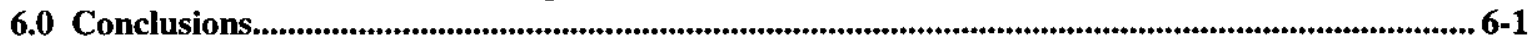


WSRC-TR-2001-00163

\section{List of Figures}

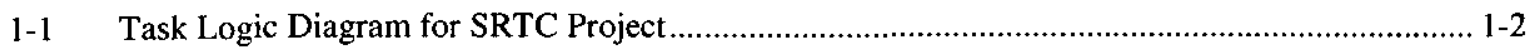

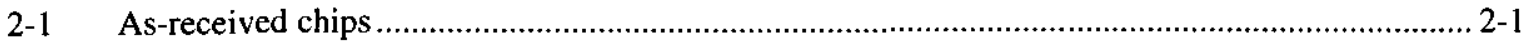

2-2 Overall photograph of largest chip as-received (topcoat-side) ....................................................... 2-2

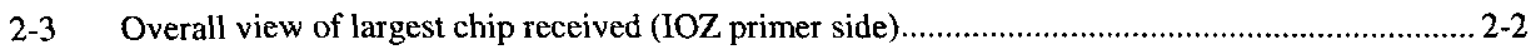

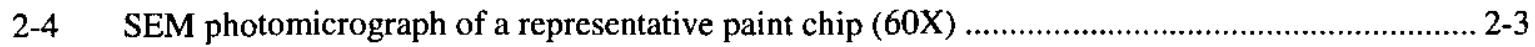

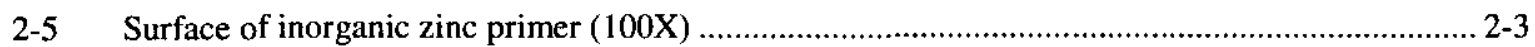

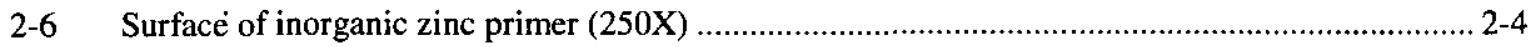

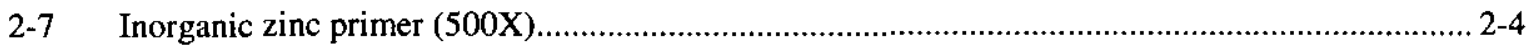

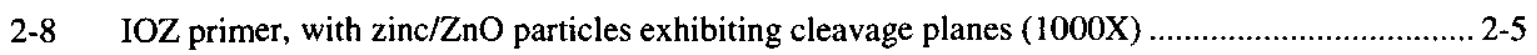

2-9 IOZ primer, zinc/ZnO particles (2000X) ............................................................................. 2-5

2-10 High magnification view of zinc particle in cleavage plane (3000X) ......................................... 2-5

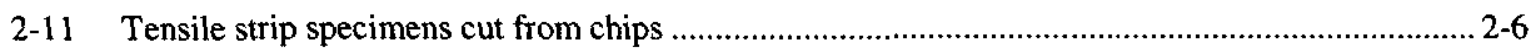

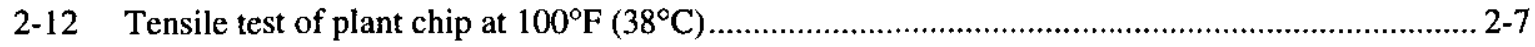

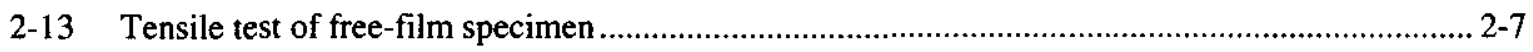

2-14 Still from video of chips before exposure to $300^{\circ} \mathrm{F}$ steam for 1 hour........................................ 2-8

2-15 Stills from video of chips after exposure to $300^{\circ} \mathrm{F}$ steam for 1 hour ............................................. 2-9

2-16 IOZ side up of chip specimen exposed to $300^{\circ} \mathrm{F}$ steam following additional radiation to $0.2 \times 10^{9} \mathrm{R}$

2-17 Analytical model of the radius of curvature of a two-layer chip ............................................... 2-10

2-18 Photograph of the artificial chips following steam exposure .......................................... 2-11

2-19 Photograph of the single-layer chips following steam exposure .......................................... 2-11

2-20 Photomicrograph of the failed chip in cross section showing the two-layer system with the Knoop hardness indents in the epoxy-phenolic and IOZ layers ................................................... 2-12

3-1 As-received coating chip, topcoat side - Rx Polar Crane location....................................... 3-1

3-2 As-received coating chip, primer (inorganic zinc) side - Rx Polar Crane location ...................... 3-2

3-3 As-received debris, ceilings/wall location, $3^{\text {rd }}$ Floor ceilings- topcoat with surfacer attached (note

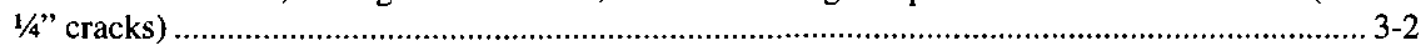

3-4 As-received chip from Rx spray - header steel location …............................................ 3-3 
3-5 Secondary electron (SE) image of inorganic zinc primer - header steel location (200X)

3-6 Backscattered image of inorganic zinc primer - header steel location (200X) (same area as Figure 3-5)

3-7 Secondary electron image of inorganic zinc primer (500X) ….................................................. 3-5

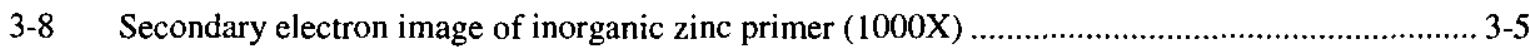

3-9 Secondary electron image of larger particle (from center of Figure 20), 2500X ........................... 3-6

3-10 Secondary electron image of larger particle, note cleavage plane (loss of clarity at high magnification), $5000 \mathrm{X}$

4-1 Overall view of snubber support base plate specimen as it appeared after DBA testing ............... 4-1

4-2 Side-view of the test specimen illustrating the extent of coating delamination .............................. 4-2

4-3 Overall view of the test specimen after removal of the failed chip ............................................... 4-2

4-4 Close-up view of the test specimen revealing identification markings in the steel plate surface beneath the failed chip

4-5 Close-up view of the surface of the steel plate beneath the failed chip illustrating the smooth, lightly brushed appearance

4-6 Overall view of the coated steel specimen provided from an operating nuclear power plant ....... 4-3

4-7 Overall view of the snubber support specimen following irradiation aging of the left half to $1 \times 10^{9}$ rads at $1 \times 10^{6} \mathrm{rad} / \mathrm{hr}$ and $120^{\circ} \mathrm{F}$ in the SRTC gamma cell ..

4-8 Overall view of the snubber support plate specimens following DBA/LOCA testing.

4-9 Front and side views of the irradiation-aged specimen illustrating the extensive blistering present following DBA/LOCA testing....

4-10 Bottom view of the irradiation-aged specimen illustrating the delamination that occurred in the immersed portion of the specimen during DBA/LOCA testing

4-11 Overall view of the irradiation-aged (yellow, front) and non-aged (white, back) specimens in room temperature water at the beginning of immersion testing

4-12 Overall view of the aged and non-aged specimens after approximately 2 hours in $200^{\circ} \mathrm{F}$ water... 4-5

4-13 Immersion test specimens following removal from the test vessel

4-14 Photomicrograph of the surface of the irradiation-aged specimen following immersion testing ... 4-6

4-15 Adhesion pull test results from the as-received snubber plate at $100^{\circ} \mathrm{F}$ and $200^{\circ} \mathrm{F}$ in the dry condition

4-16 Overall views of the handrail specimen as it appeared as-received and after dividing in half (left), and after irradiation-aging of half of the specimen (right)

4-17 Overall view of the handrail specimens, after DBA-LOCA testing 
4-18 Macroscopic view of the surface of the irradiation-aged specimen, revealing the presence of intact blisters.

4-19 Microscopic view of the surface of the irradiation-aged handrail specimen, following DBA-LOCA testing.......

4-20 Handrail specimens immediately after immersion in water preheated to $200^{\circ} \mathrm{F}$ 4-10

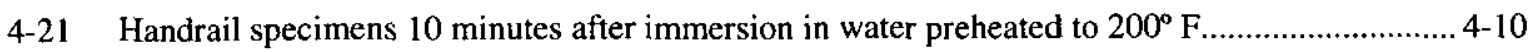

4-22 Handrail specimens at the end of the immersion tests......................................................

4-23 Irradiation-aged handrail specimen after removal from the water immersion test................... 4-11

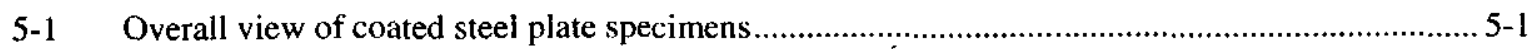

5-2 Overall view of one of the coated plate specimens as it appeared prior to immersion testing $\ldots . . .5-1$

5-3 Overall view of the coated plate specimen as it appeared after immersion in $200^{\circ} \mathrm{F}$ water for approximately 24 hours. 


\subsection{Introduction}

Nuclear power plants (NPPs) must ensure that the emergency core cooling system (ECCS) or safety-related containment spray system (CSS) remains capable of performing its design safety function throughout the life of the plant. This requires ensuring that long-term core cooling can be maintained following a postulated loss-of-coolant accident (LOCA). Adequate safety operation can be impaired if the protective coatings which have been applied to the concrete and steel structures within the primary containment fail, producing transportable debris which could then accumulate on BWR ECCS suction strainers or PWR ECCS sump debris screens located within the containment.

Service Level I coatings were used on the interior containment steel shells, concrete walls and floors, and other structures, thereby providing environmental protection to these substrates and facilitating decontamination, as necessary. The coatings were applied during plant construction, and the assumption has been that properly selected and applied "qualified" coatings would not fail during the normal plant design life (i.e., 40 years) plus exposure to a DBA-LOCA, except for minor local damage due to mechanical impact or cleaning chemicals. However, there is clear evidence for failure of qualified coatings during plant design life. These failures raised questions regarding the ability of aged coatings to remain attached during accident conditions, and additionally, regarding the characteristics of any debris which might form as a result of these conditions. These questions were the basis for the Nuclear Regulatory Commission Office of Nuclear Regulatory Research, Division of Engineering Technology, initiating a program through the Savannah River Technology Center (SRTC) to research the properties and performance of aged Service Level I coatings (Reference 1).

The logic diagram for the SRTC program, shown in Figure 1, has included the following key areas of investigation, among others:

- Determination of the thermal, mechanical, and physical properties of the coating systems commonly used in the nuclear industry,

- Development of mathematical models to hypothesize the performance of the coating systems under the thermal and mechanical stresses which would be induced during large-break loss-of-coolant accident conditions, and

- Duplication of original coating qualification tests on recently applied, artificially-aged, and plant-aged specimens.

Several documents describing the progress of this research have been published previously, and are avaitable to the public from the NRC (References 2, 3, and 4). Those reports addressed the investigation of artificially-aged specimens, exclusively. This document will present the data collected during the investigation of coating specimens from plants. 


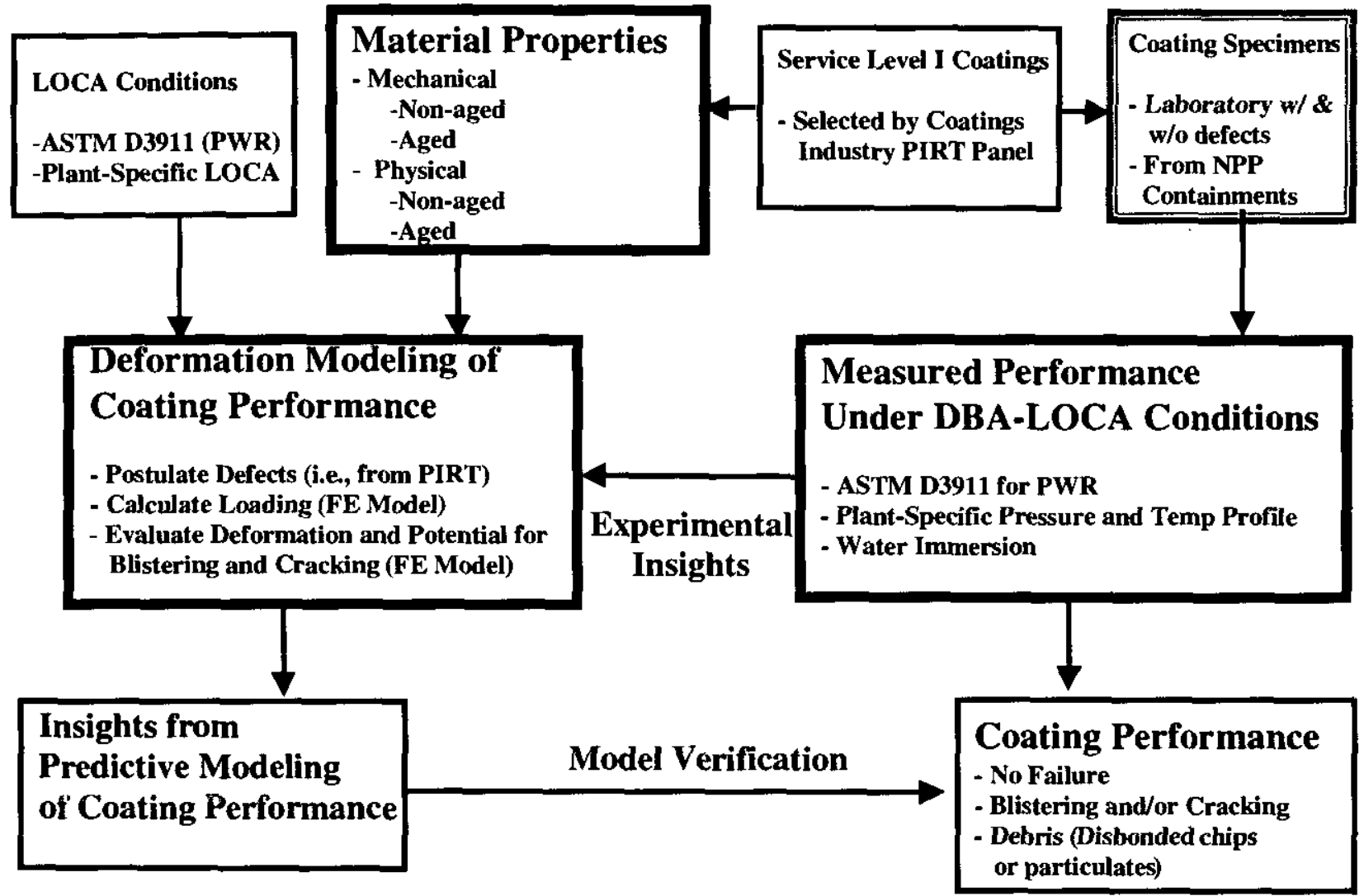

Figure 1-1. Task Logic Diagram for SRTC Project

Sections 2 and 3 of this document describe the examination of samples of failed coatings from two different power plants, along with a postulated cause of their failure. Representative samples of intact coatings were obtained from two other plants following exposure to operating plant conditions for upwards of 20 years. Testing them according to the ASTM specifications currently used for qualification of Service Level I coating systems offered a unique opportunity to investigate the consequences, if any, of plant exposure on coating performance. The results of these tests are described in Sections 4 and 5. Conclusions drawn from this study are presented in Section 6.

This is the first time a comprehensive investigation into the performance of service-aged coatings has been performed. In order to fully evaluate the effects of aging on the performance of Service Level I coatings, efforts were made to obtain representative samples of failed and intact coatings from as many operating nuclear power plants, as possible. Ideally, coating systems representing a range of product types, times in service, exposure conditions, etc. would have been made available to correlate to the artificially-aged specimens previously tested. Unfortunately, it proved to be difficult to obtain coating specimens, due to constraints in plant operating and maintenance schedules, and, perhaps, trepidation on the part of some utilities. In fact, the program was never able to obtain a specimen of a Service Level I coating applied on concrete. Even when plants were willing and/or able to cooperate, it was difficult to obtain precise information about coating service and radiation exposure conditions. Therefore, the data presented in this document do not provide a complete understanding of the effects of age and service on the performance of the Service Level I coating systems in use today. Additional data from plant specimens would be useful in developing a full understanding of the effects of time and operating conditions on coating performance. 
We would like to express our sincere appreciation to the NRC, to Mr. Jon Cavallo, and to the operators of the participating nuclear generating stations for their help in collecting the specimens described in this document. Without their cooperation and patience responding to the myriad questions from the researchers, this program could not have been completed.

\section{References:}

1. "Supplemental User Need Request Regarding Potential For Loss of Emergency Core Cooling For a Pressurized Water Reactor Due to LOCA Generated Coating Debris Clogging the Containment Sump Screens," Collins, S., Memorandum to Morrison, D., U.S. Nuclear Regulatory Commission, Washington, DC, June 2, 1997.

2. "Degradation and Failure Characteristics of NPP Containment Protective Coating Systems (U) Interim Report", WSRC-TR-2000-00079, March 2000, (USNRC Public Electronic Reading Room, ADAMS Accession No. ML003703890).

3. "Degradation and Failure Characteristics of NPP Containment Protective Coating Systems (U) SRTC Coating System No. 2", WSRC-TR-2000-00340, October 2000, (USNRC Public Electronic Reading Room, ADAMS Accession No. ML003772811).

4. "Degradation and Failure Characteristics of NPP Containment Protective Coating Systems (U) SRTC Coating System No. 1", WSRC-TR-2001-00067, February 2001, (USNRC Public Electronic Reading Room, ADAMS Accession No. ML010600462). 


\subsection{Failed Coating Chips - Plant Number 1}

During a refueling outage at a commercial nuclear power generating station, the USNRC resident inspector noticed paint peeling or delaminating (or disbonding) off the containment wall outside the missile shield. This coating system had been qualified per Regulatory Guide 1.54, and consists of an IOZ primer (Carbozinc ${ }^{\otimes}$ 1 1SG) and an epoxy-phenolic topcoat (Phenoline ${ }^{\otimes} 305$ Finish). The topcoat was observed to be disbonding from the primer, with some primer still intact and bonded to the topcoat. The licensee's preliminary root cause of failure/degradation is that the IOZ primer application was possibly too thick (manufacturer recommended dry film thickness is 2-3 mils or 50-75 microns per coat), improperly thinned, or inadequately prepared prior to topcoating, and the primer failed cohesively. This coating system was applied relatively recently, with the majority of application performed during 1984-1985.

\subsection{Debris Characterization - General Observations}

The coating chips were submitted to the SRTC metallurgical laboratory for characterization via scanning electron microscopy (SEM), energy dispersive X-ray (EDS), X-ray diffraction (XRD), and Fourier Transform Infrared (FT-IR) spectrophotometry. Samples varied in size from several inches in length and up to 1 " to $1-1 / 2$ " wide to very small chip fragments. Although packaged very well, some chips were assumed to have been fractured during shipping and handling due to the relatively brittle nature of this particular coating system. Therefore, the actual "as-failed" size/shape distribution is unknown.

As shown in Figure 2-1, the larger chips exhibited significant concavity and curvature, indicative of high tensile stress development during curing due to solvent evaporation. This particular coating (Phenoline ${ }^{\circledast}$ 305 Finish) is approximately $64 \%$ solids with a volatile organic content of $2.43 \mathrm{lbs} / \mathrm{gal}$.

The topcoat is off-white and the IOZ primer is gray in color. A close-up view of the largest coating chip is shown in Figures 2-2 and 2-3, with the topcoat side up. Although the primer was observed to be well adhered to the topcoat, powder residue was readily removed during routine handling. In addition, the topcoat thickness appeared to be greater than that of the primer adhered to the topcoat. The amount of primer remaining on the substrate is currently unknown. It is assumed that the majority of primer thickness was left on the carbon steel substrate.

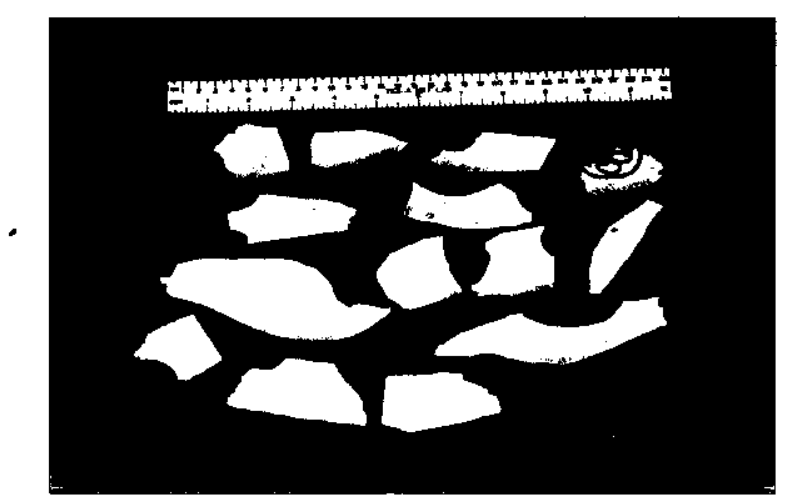

Figure 2-1. As-received chips 


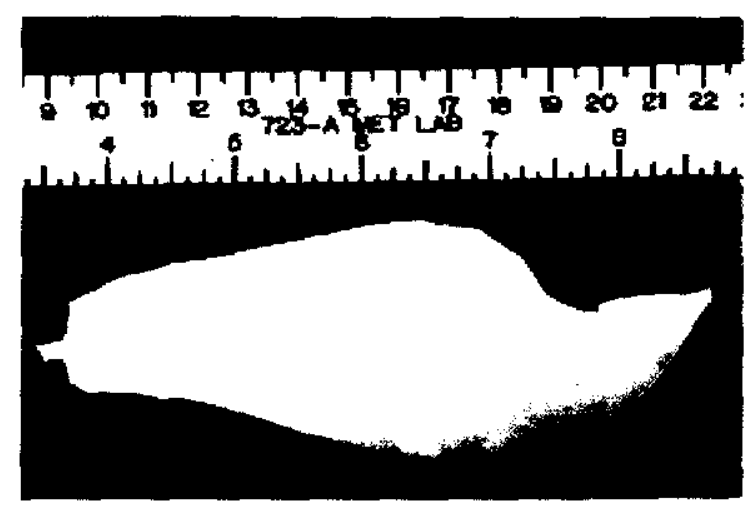

Figure 2-2. Overall photograph of largest chip as-received (topcoat-side)

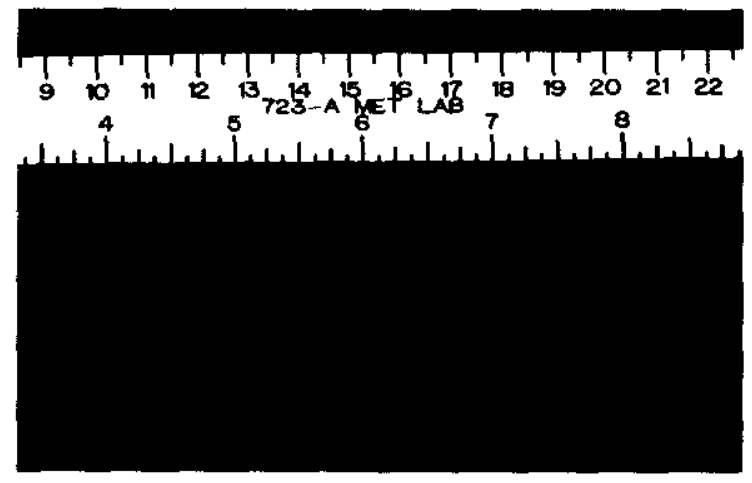

Figure 2-3. Overall view of largest chip received (IOZ primer side)

\subsection{Scanning Electron Microscopy (SEM) Examination}

The chip samples were examined using an SEM to reveal surface morphology and characteristics of the $\mathrm{IOZ}$ primer. Samples were examined using a Hitachi scanning electron microscope at low voltage (10$20 \mathrm{KV}$ ). A low magnification view of a chip sample is shown in Figure 2-4, with the topcoat (white) charging slightly due to its non-conducting nature. Samples were grounded in the microscope using conductive carbon tape to minimize such effects. Non-conducting samples can be sputter-coated with gold or carbon, but surface defects and other important features can often be masked or covered at microscopic levels. From Figure 2-4, the overall chip thickness was estimated to be approximately 180 microns or approximately 7 mils. Although only a rough estimate from an angular view, this is consistent with a 4-6 mil thick topcoat and a 2-3 mil primer which has cohesively split (2-3 mils for the primer would be acceptable, with all other application factors ideal). 
WSRC-TR-2001-00163

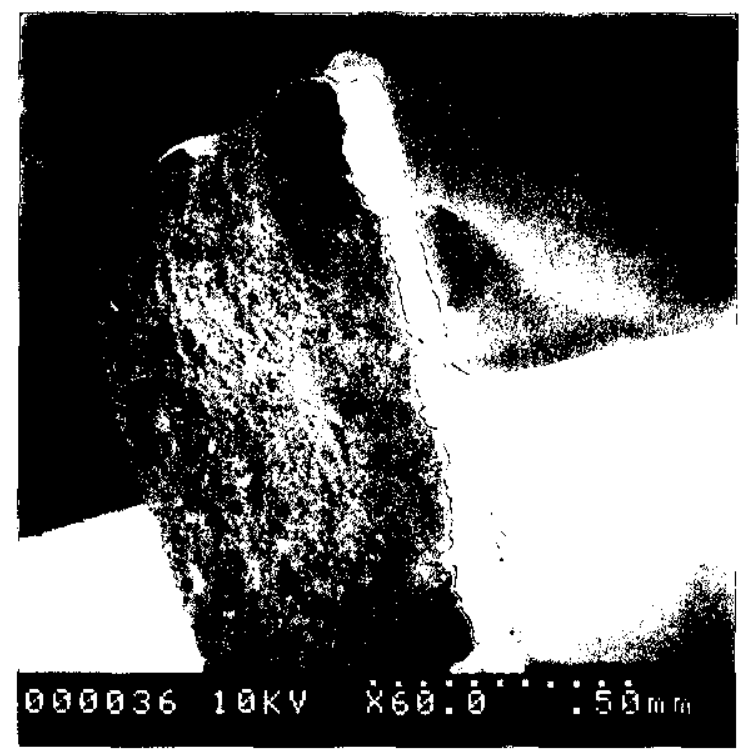

Figure 2-4. SEM photomicrograph of a representative paint chip (60X)

In Figures 2-5 to-2-10, higher magnification views are shown, with zinc/zinc oxide $(\mathrm{ZnO})$ particles observed to be relatively spherical and intact. Although difficult to ascertain after disbondment, the presence of such uniformity indicates that the topcoat possibly failed initially due to tensile stress in the topcoat that was not supported by the IOZ primer layer. That is, tensile stresses would be expected in a coating for which volatilization of the carrier material occurs. This condition, coupled with the (assumed) low cohesion strength within the IOZ, due to possible non-uniform distribution of the ethyl silicate binder as a result of inadequate moisture and/or excessive thickness, led to cracking in the topcoat and splitting within the IOZ layer to form chips.

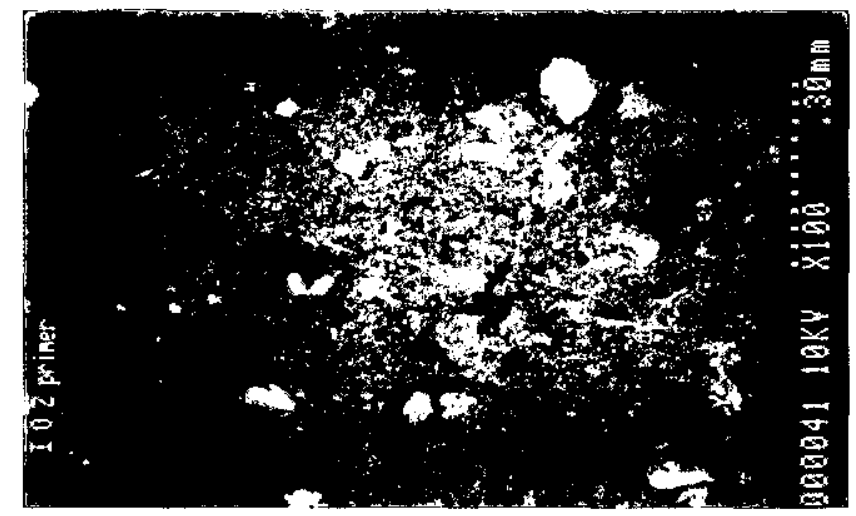

Figure 2-5. Surface of inorganic zinc primer (100X) 


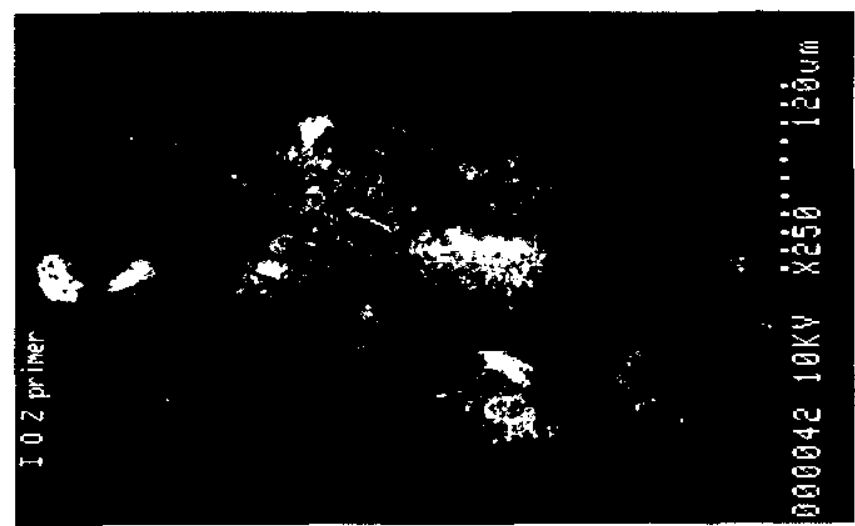

Figure 2-6. Surface of inorganic zinc primer (250X). (white particles are assumed to be charged regions of the epoxy-phenolic topcoat)

At 500X (Figure 2-7), zinc oxide particles were estimated to be approximately 10-30 microns in diameter, which closely corresponds with observations made in other studies of similar systems. Although most particles were intact, some of these were believed to have been disturbed during failure and during subsequent handling and motion. Surface particles present were believed to be dust that was lightly adhered to the underlying layers and were not necessarily representative of the actual fracture interface. Examination of the fracture surface in such a material is therefore more difficult than for a rigid crystalline material. At higher magnifications (Figures 2-8 to 2-10), cleavage or fracture lines on spherical particles were more obvious. At higher magnifications, discrimination of these features became more difficult due to low voltage beam fluctuations and surface contrast.

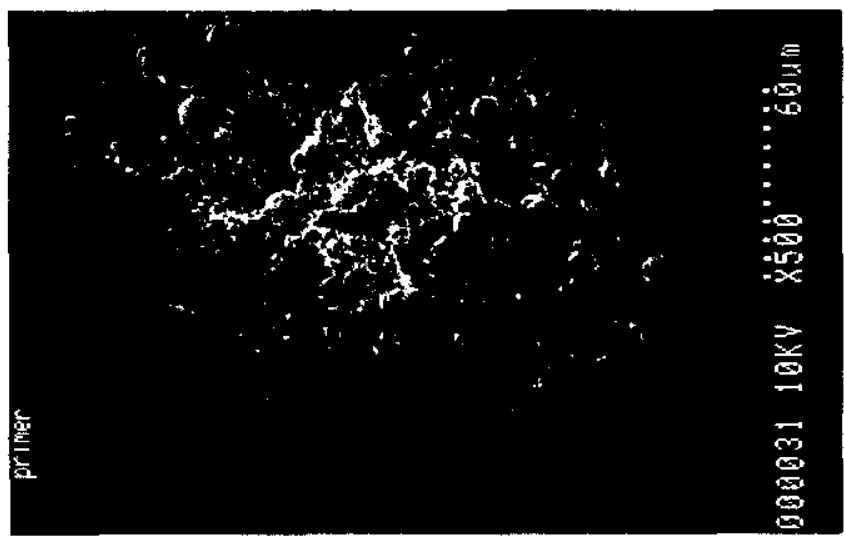

Figure 2-7. Inorganic zinc primer (500X). 


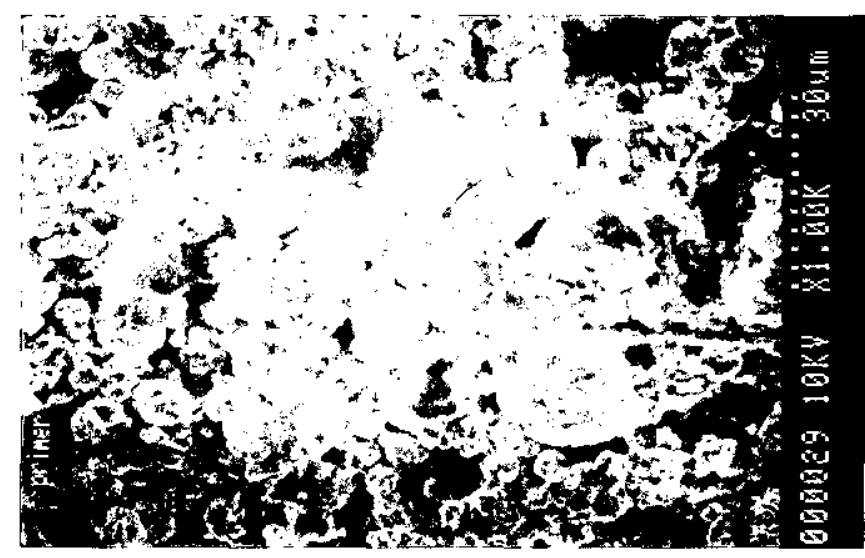

Figure 2-8. IOZ primer, with zinc/ZnO particles exhibiting cleavage planes (1000X)

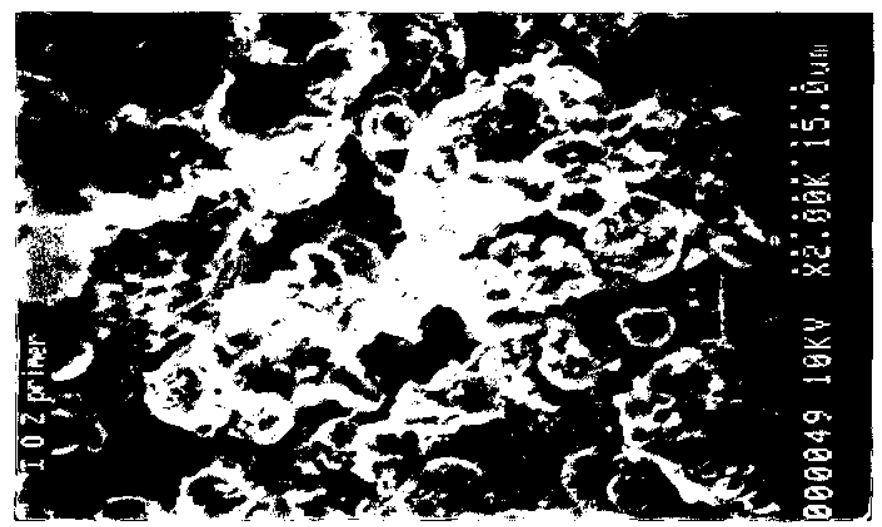

Figure 2-9. : $O Z$ primer, zinc/ZnO particles (2009X)

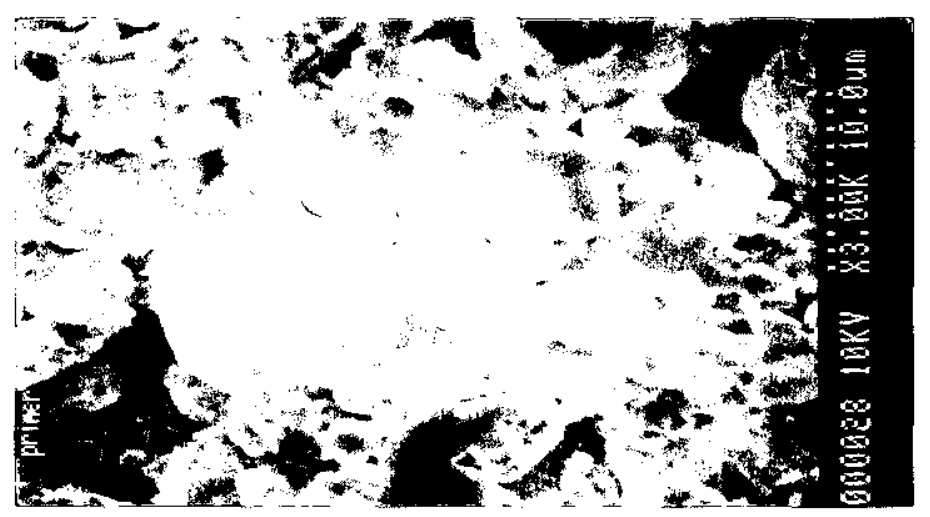

Figure 2-10. High magnification view of zinc particle in cleavage plane $(3000 \mathrm{X})$

\subsection{X-Ray Diffraction}

In addition to EDS analysis, X-ray diffraction was performed to determine the presence of zinc oxide versus metallic zinc and to identify/confirm the presence of unreacted silicates and/or asbestos fillers and other oxides, silicates, etc. X-ray analysis of the primer revealed major peaks for both zinc and zinc oxide, indicating that the metallic zinc dust in the primer had oxidized to varying degrees, which was likely dependent upon oxygen availability and the presence of moisture during the primer cure. In the topcoat, the 
primary peak detected was that of rutile or titania ( $\mathrm{TiO} 2)$, which is the primary pigment in the off-white topcoat.

\subsection{Tensile Testing}

Free-film tensile tests were developed using fragments or chips of an epoxy-phenolic/lOZ coating system which failed in service. The strip specimens were die-cut in widths of 0.35 in. (Figure 2-11). Specimens were tested (Figure 2-12) in an Instron model 4507 mechanical testing machine at a crosshead speed of 0.05 inches per minute, using knurled, spring-loaded grips. Failure occurred outside the grips (Figure 2-13) in only one successful test, at $100^{\circ} \mathrm{F}$. The maximum load was $2.7 \mathrm{lb}$ and the resulting tensile strength 710 psi. Other tests resulted in failure within a grip. The 710-psi tensile strength is lower than that measured in an unirradiated, freshly applied epoxy phenolic coating (without any primer layer), but is within the range seen in the same coating irradiated to $10^{9} \mathrm{rad}$.

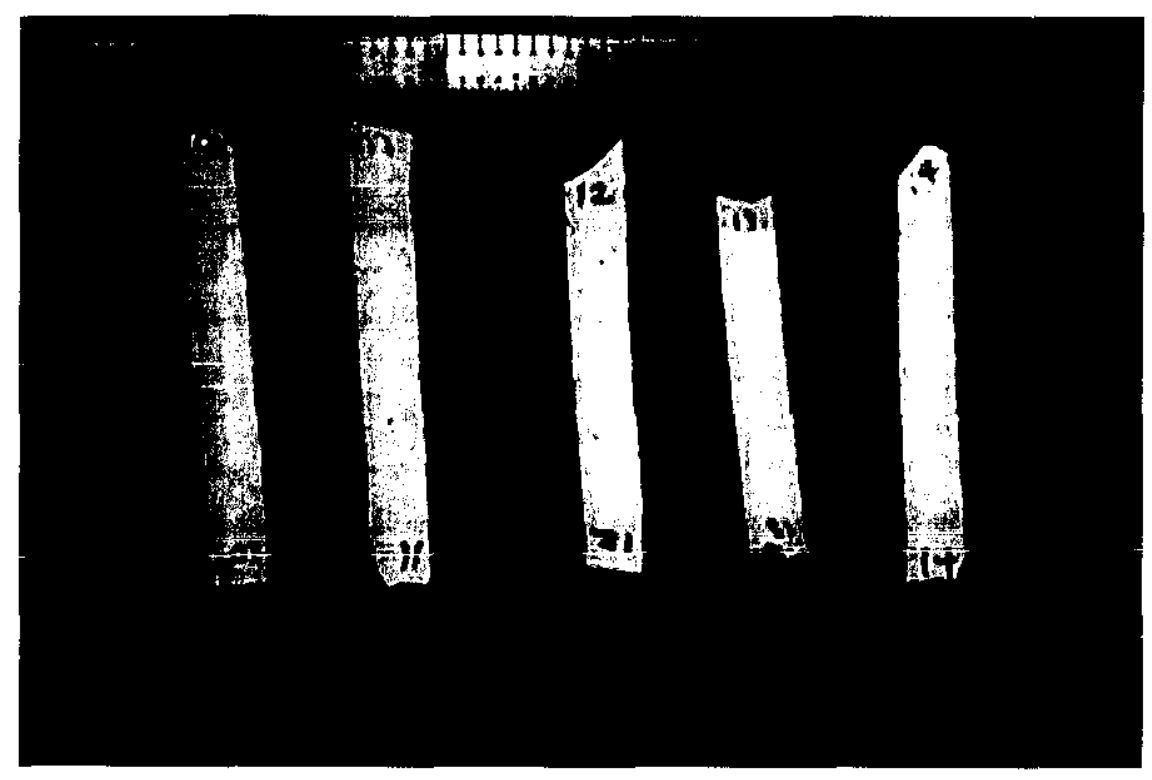

Figure 2-11. Tensile strip specimens cut from chips 
Plant Chip Tensile Test, Specimen $10 @ 38$ deg C failed outside grips

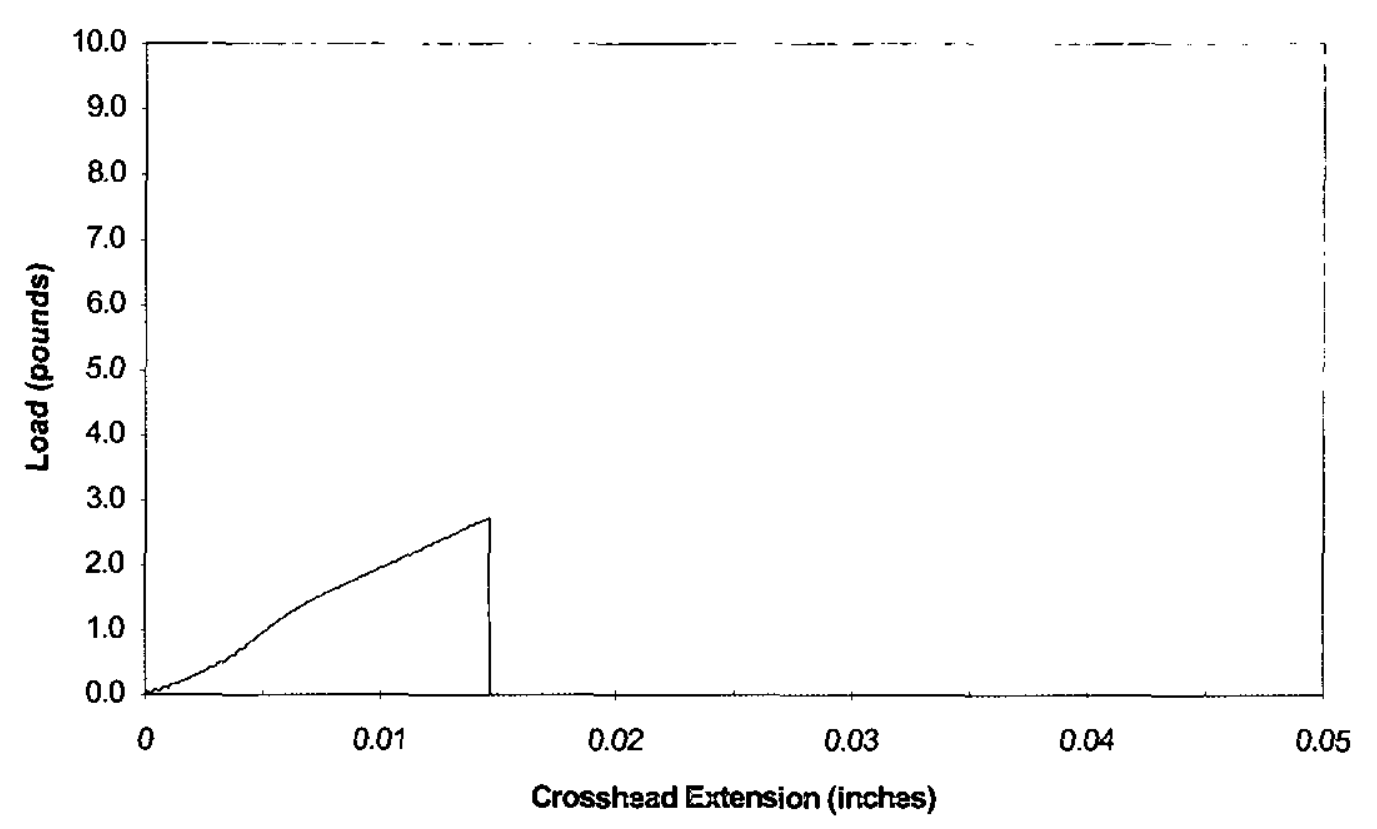

Figure 2-12. Tensile test of plant chip at $100^{\circ} \mathrm{F}\left(38^{\circ} \mathrm{C}\right)$

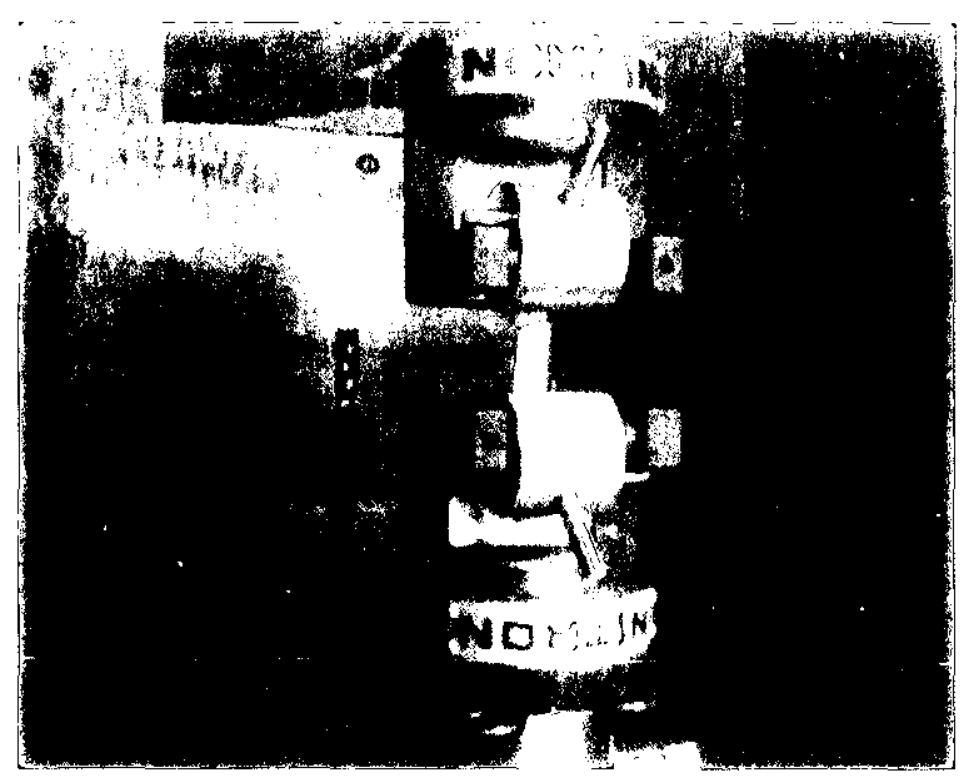

Figure 2-13. Tensile test of free-film specimen 


\subsection{DBA LOCA Testing}

A real-time videotape record of the response of the chips was made during a simulated DBA/LOCA exposure. Figures 2-14 and 2-15 show stills from this video before and after exposure. The chips were in the following initial conditions:

- As-received

- Irradiated to $0.2 \times 10^{9} \mathrm{R}$ at $1 \times 10^{6} \mathrm{R} / \mathrm{hr}$ in the SRTC gamma cell facilities

- Ground to remove the 0.005 " of IOZ layer to effectively make a single epoxy-phenolic layer chip specimen.

The as-received specimens had an initial curl or "curl-bias." During chamber heat-up the chips showed an initial relaxation of this curl followed by a re-curl to the initial or even greater curled condition. With steam exposure, extreme tight curling occurred at a relatively constant rate throughout the first approximately 30 minutes. A relatively minor amount of additional curling occurred beyond the first 30 minutes. A large loss of powder from the specimen was observed on the specimen holder plate. The specimens also showed an approximate $20 \%$ loss in weight. The specimens always curled with the IOZ layer on the outside and the epoxy-phenolic layer on the inside. No consistent trend of final curl direction with respect to the initial bias was noted. The steam exposure greatly softened the chips and allowed plastic flow. The effects of temperature and moisture have been observed to soften the epoxy-phenolic [ref. WSRC-TR-2001-00067]. Qualitatively, the brittleness of the exposed (curled) specimens was regained at room temperature.

The pre-irradiated specimens did not curl to the extent of the non-irradiated specimens. The irradiation embrittled the chips, as qualitatively noted by the reduction in ability to bend the specimens before breaking for the irradiated chips, compared to the non-irradiated chips. The steam exposure softened the chips and allowed plastic flow, since bending in excess of that at room temperature was observed. The IOZ layer of the iradiated chips was also observed to contain numerous smail cracks foilowing the steam exposure, as shown in Figure 2-16. This was in contrast to the non-irradiated exposed chips, which did not show formation of cracks.

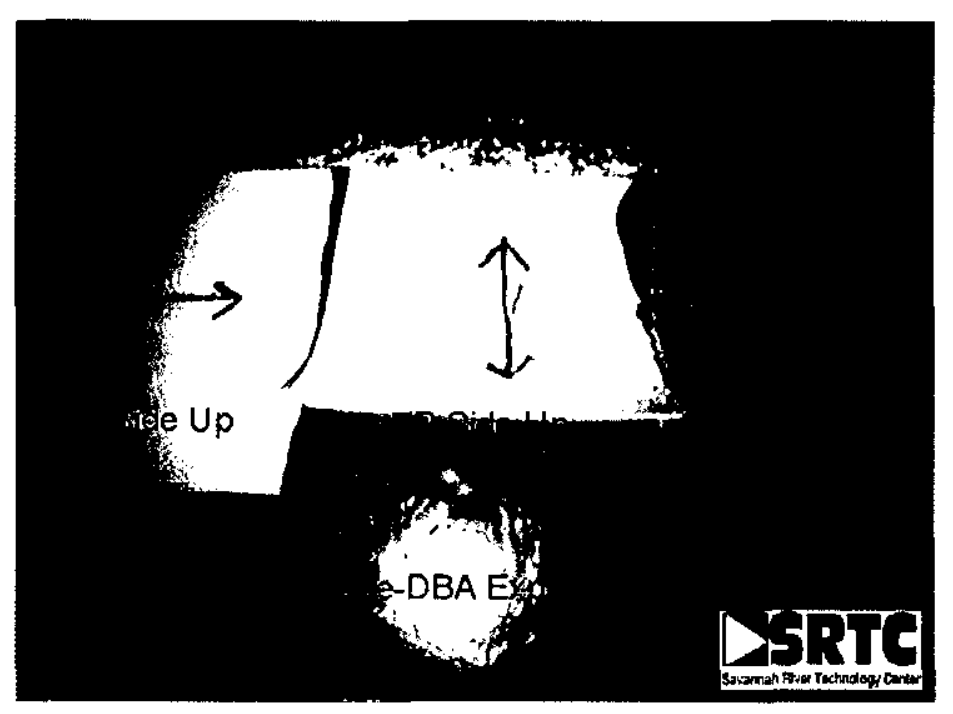

Figure 2-14. Still from video of chips before exposure to $300^{\circ} \mathrm{F}$ steam for 1 hour 


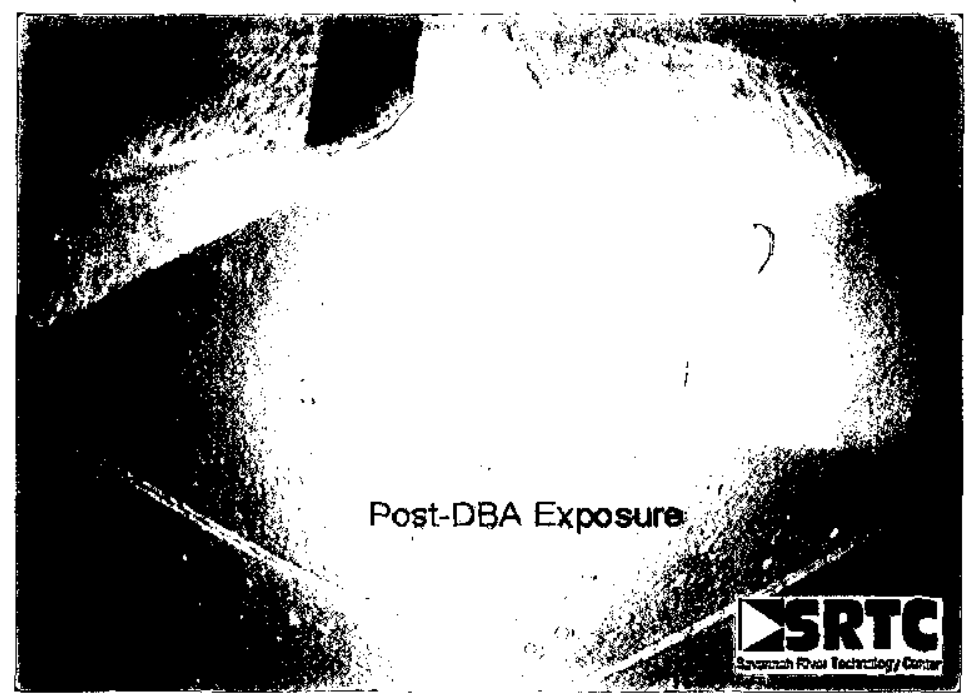

Figure 2-15. Stills from video of chips after exposure to $300^{\circ} \mathrm{F}$ steam for 1 hour

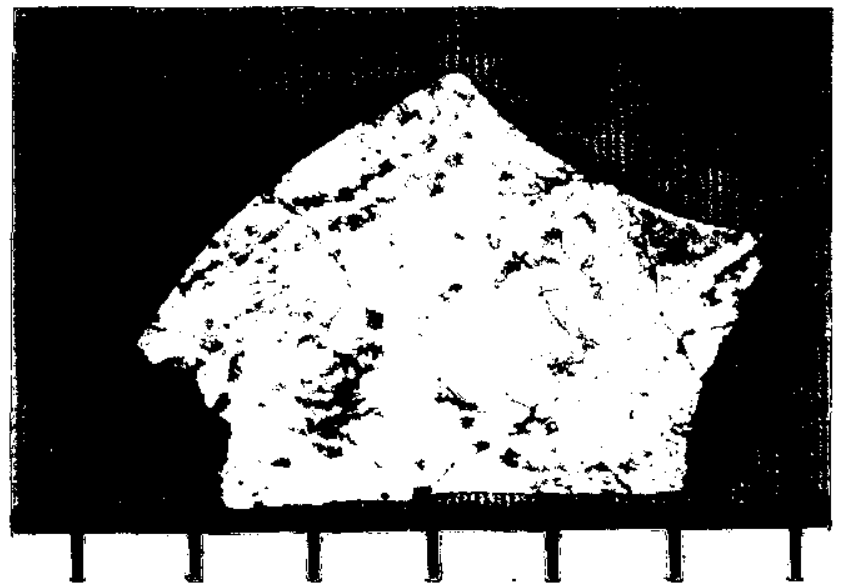

Figure 2-16. IOZ side up of chip specimen exposed to $300^{\circ} \mathrm{F}$ steam following additional radiation to $0.2 \times 10^{9} \mathrm{R}$.

\subsection{Analytical Modeling of Two-Layer Coating}

A mechanics model of a two-layer coat chip that would exhibit curling was constructed and an example case was analyzed. Curling of two-layer system must be caused by a relative difference in expansion or contraction. The approximate solution is:

$$
\varepsilon_{\mathrm{o}}-\varepsilon_{\mathrm{i}}=\delta / 2 \mathrm{r}
$$

where $\delta$ is the total thickness of the two-layer chips, $r$ is the radius of curvature, and $\varepsilon_{o}-\varepsilon_{\mathrm{i}}$ is the relative difference in expansion or contraction. 


\section{Topcoat}

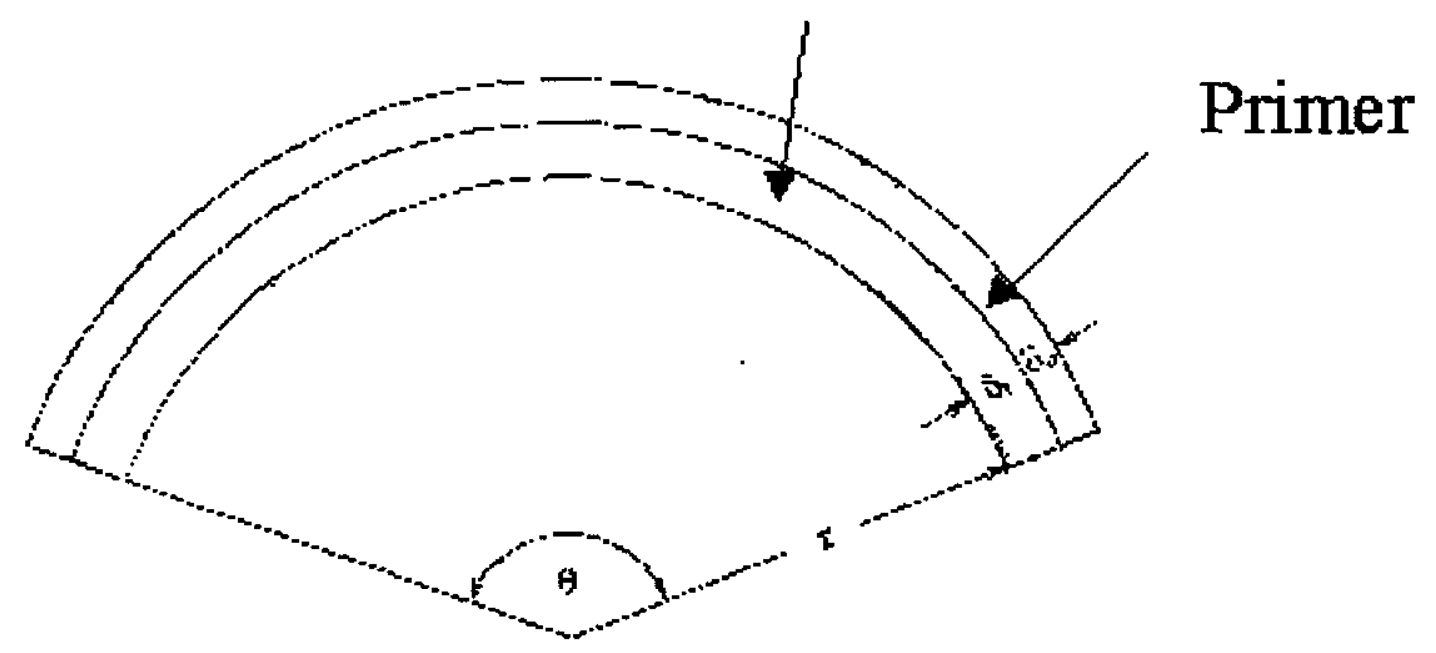

Figure 2-17. Analytical model of the radius of curvature of a two-layer chip

This model shows that, whatever the mechanisms causing the differential expansion or contraction, a difference in expansion/contraction must occur if the chips curl. The as-received chips had an initial radius of curvature of approximately $1 \mathrm{~cm}$, consistent with a differential expansion/contraction of approximately one percent.

There are two mechanisms that could cause differential expansion namely (i) oxidation of the porous zinc primer layer and (ii) the differences in thermal expansion characteristics between the layers. Analyses evaluating each of these phenomena were performed and are summarized below.

$$
\text { Oxidation of Zinc Layer }
$$

The results show that volume expansion of 30 percent could occur for non-reacted zinc. This would provide up to approximately 10 percent liner expansion and therefore provide a differential expansion sufficient to cause curling to radii approximately $1 \mathrm{~mm}$. The parametric analysis considered the packing densities of spheres of zinc and the thickness of the zinc layer.

$\mathrm{X}$-ray diffraction and SEM-EDS analysis of the post-DBA chips were performed to determine if a difference in the amount of $\mathrm{ZnO}$ before and after exposure could be quantified to compare to the analytical results. The results from these analyses indicate that additional oxidation of the $\mathrm{Zn}$ has occurred.

Thermal Expansion

The results show that differences in thermal expansion coefficients can result in curling of a two-layer chip, similar to a "bi-metallic" strip.

To test the hypothesis that a single-layer system should not be subject to the high degree of curling because differential expansion/contraction could not occur (unless the single-layer was not uniform), tests were run with single-layer coats. First, specimens of "artificial" debris chips, prepared by LANL for transport tests, were exposed to $300^{\circ} \mathrm{F}$ steam for 1 hour. The artificial chips exhibited only minor deformation compared to the plant-provided chips (Figure 2-18). Next, single-layer specimens were prepared by carefully grinding off the 0.005 " IOZ layer on the chips using 1200 grit paper. Some residual IOZ remained at the edges of the chips, since it was difficult to remove this layer without breaking the chips. 


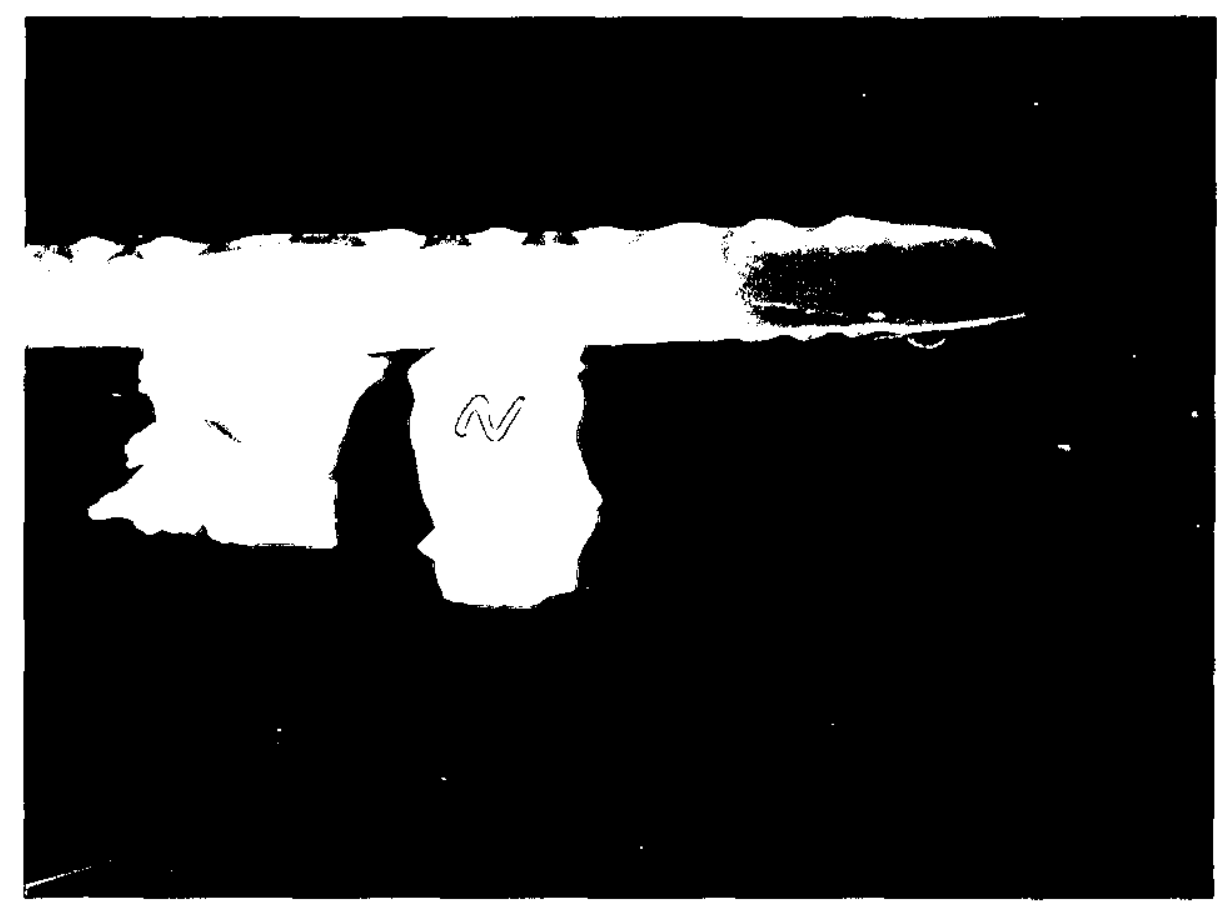

Figure 2-18. Photograph of the artificial chips following steam exposure

The single-layer chips were exposed to $300^{\circ} \mathrm{F}$ steam for 1 hour and the results (Figure 2-19) showed only minor curling of the chips compared to the results from the two-layer chips.

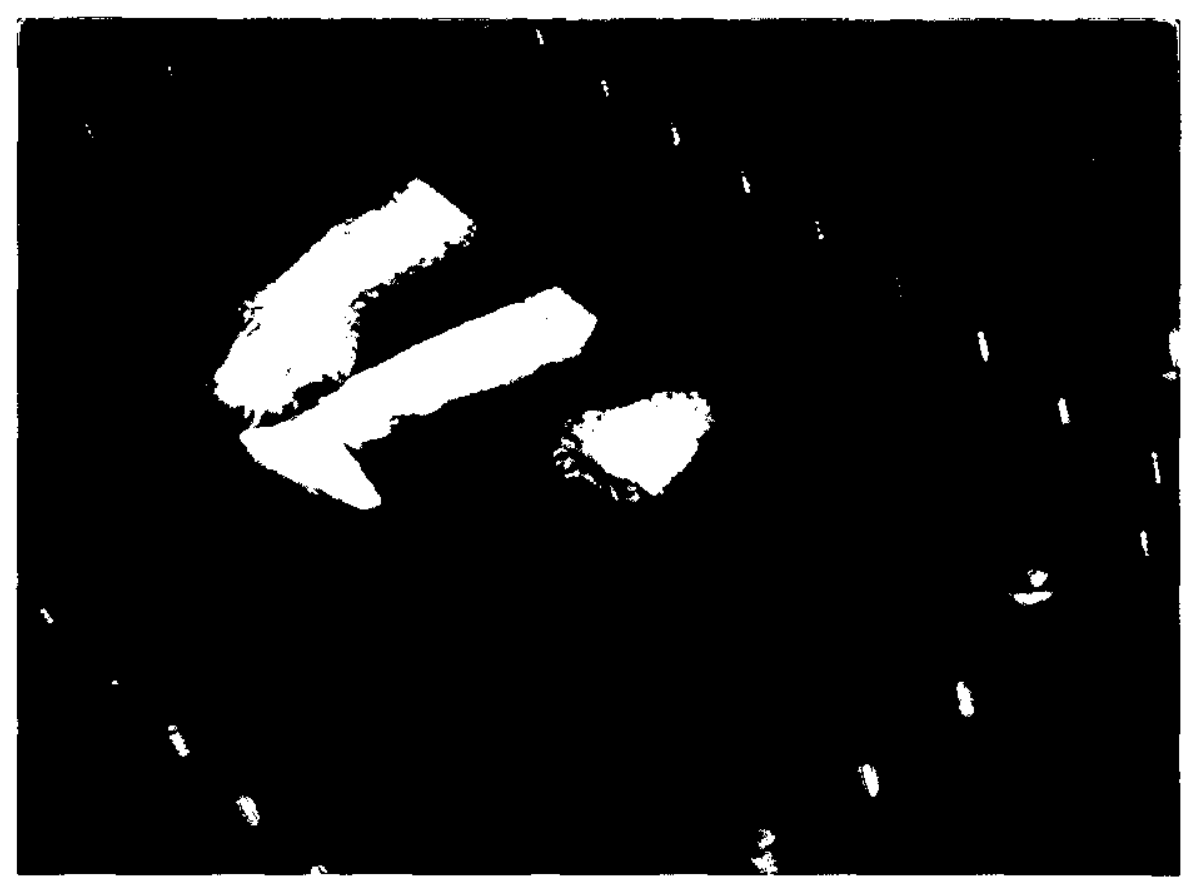

Figure 2-19. Photograph of the single-layer chips following steam exposure 


\subsection{Metallography}

Additional characterization of the failed chips was performed. The as-received chips were mounted in cross-section and polished to show the two-layer system (see Figure 2-20). The Knoop hardness (HK) was determined using a $10 \mathrm{gram}$ load. Measurements were made in the epoxy-phenolic layer with an average hardness number of $15.9 \mathrm{HK}$ of five data $(17.3,15.5,15.9,15.8,14.8)$. Measurements in the IOZ layer were more difficult to make because the contrast of the structure obscured the indentation. The average hardness number is $33.4 \mathrm{HK}$ of three data $(44.9,28.2,27.2)$.

This characterization information provides an assessment of the strength of the coatings, since hardness can be correlated with yield strength.

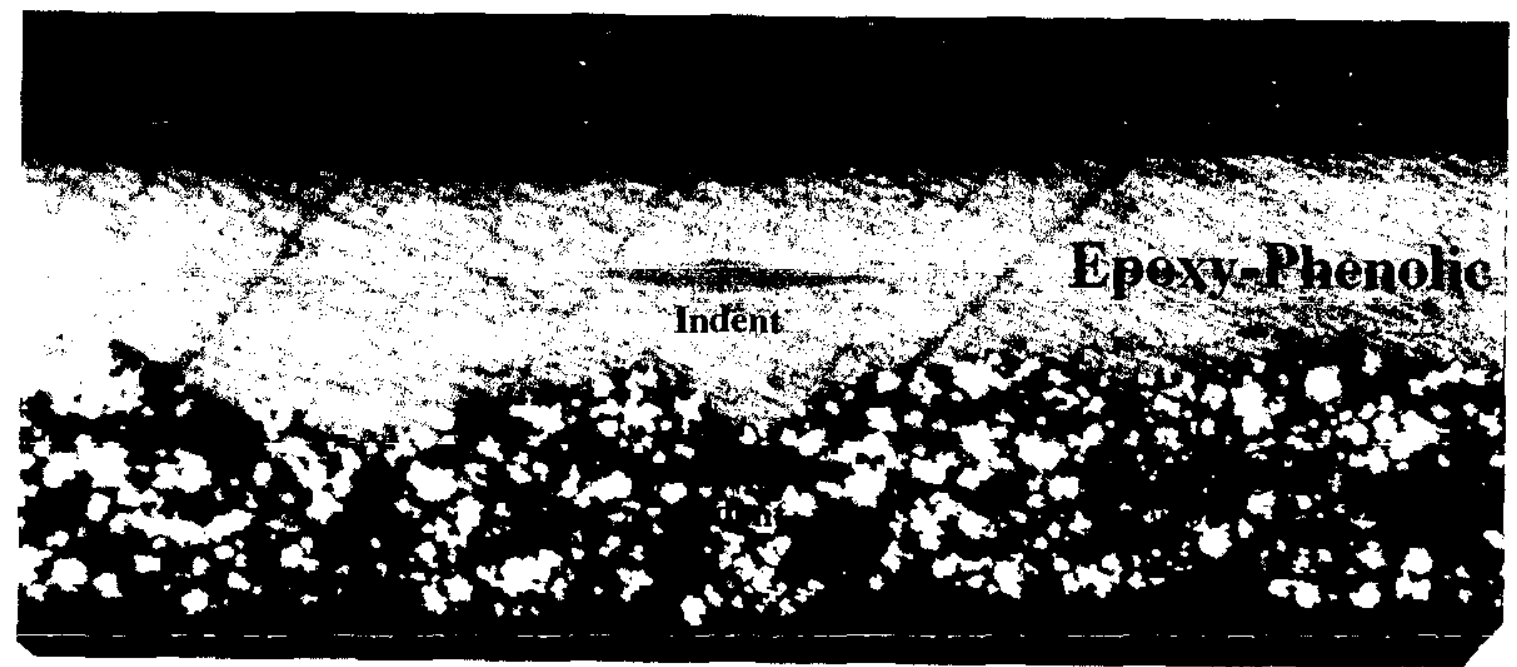

Figure 2-20. Photomicrograph of the failed chip in cross section showing the two-layer system with the Knoop hardness indents in the epoxy-phenolic and IOZ layers 


\subsection{Failed Coating Chips - Plant Number 2}

\subsection{Sample Description}

Samples of coating chips were received from an operating nuclear power generating station. Although the chips were appropriately labeled and transported as non-radioactive material, due to residual levels of contamination and possible hot particles, these samples were treated as contaminated and handled accordingly.

Three different bags were received, each with coating debris/chips from different areas/locations in the primary containment structure. The bags were labeled as "Rx B East, $3^{\text {rd }}$ floor, ceilings \& wall", "RX spray, header steel", and "Rx Polar Crane", respectively. Representative photographs of as-received chips are shown in Figures 3-1 to 3-4. The coating system used was Carboline Phenoline 305 Finish/topcoat with either CarboZinc 11 inorganic zinc primer (steel substrates) or Phenoline 305 primer (concrete substrates), according to plant representatives.

The samples were typically 1 " square or less, generally smaller than the as-received chips described in Section 2, with less curling bias, indicative of curing stresses and/or excessive film thickness. There also appeared to be much less primer attached to the topcoat for these particular chips than for the other chips.

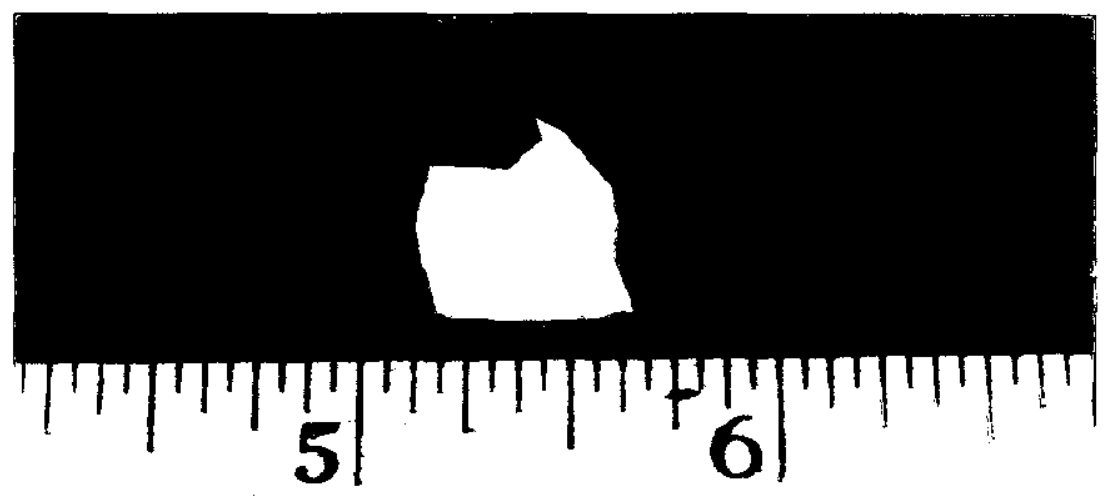

Figure 3-1. As-received coating chip, topcoat side - Rx Polar Crane location 


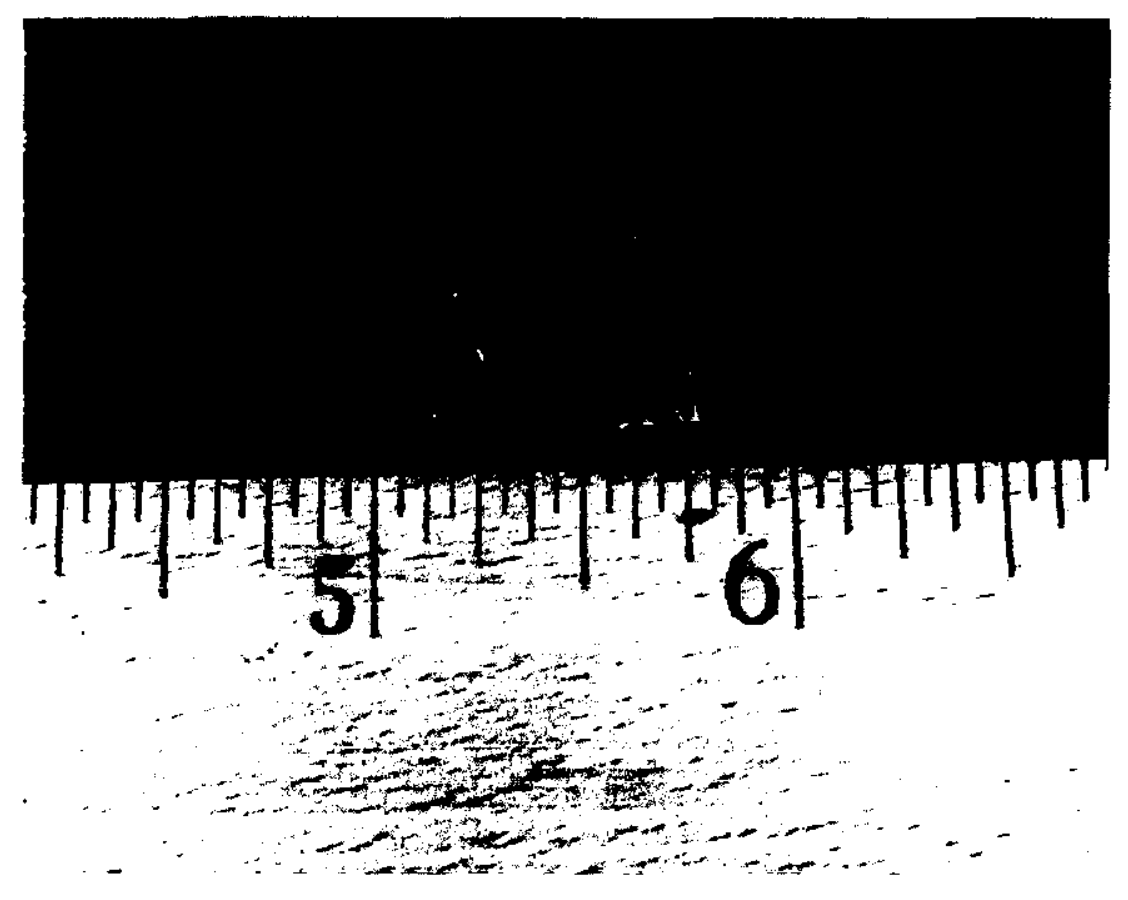

Figure 3-2. As-received coating chip, primer (inorganic zinc) side - Rx Polar Crane location

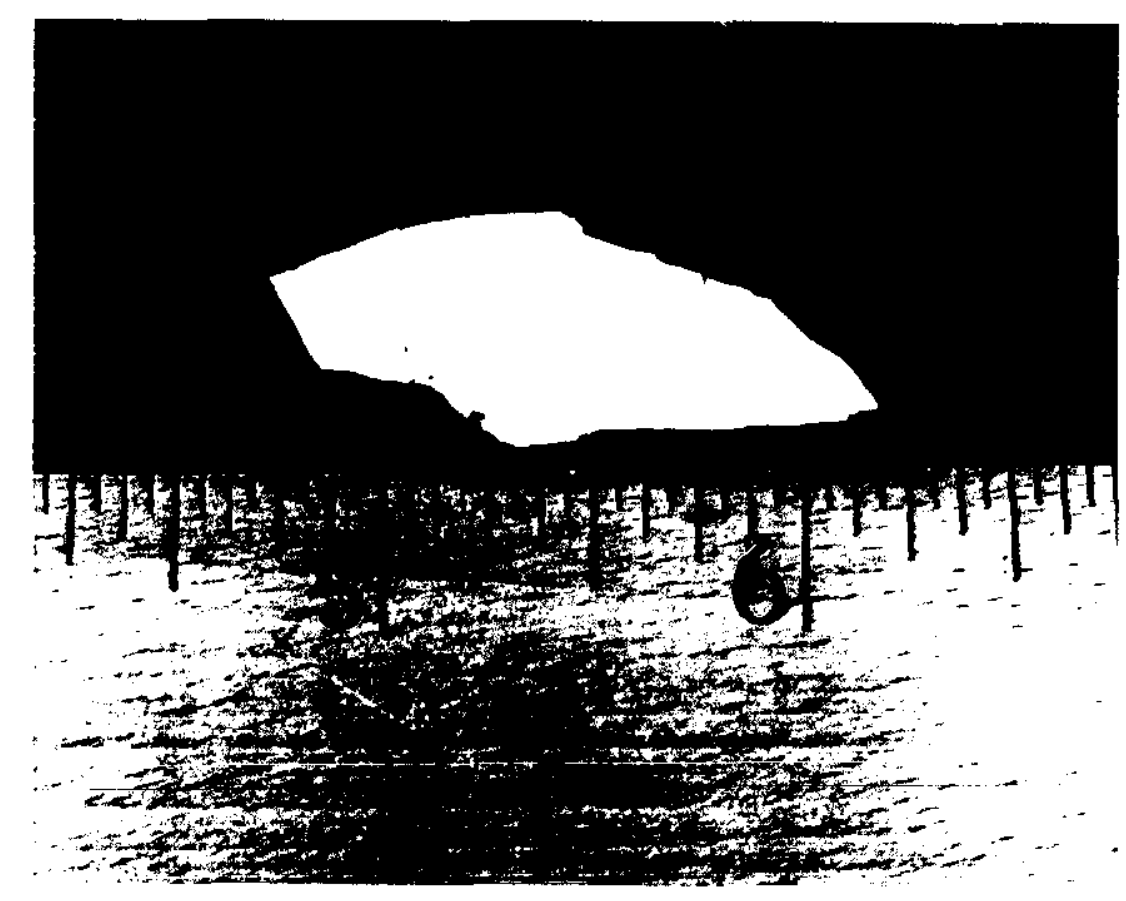

Figure 3-3. As-received debris, ceilings/wall location, $3^{\text {rd }}$ Floor ceilings- topcoat with surfacer attached (note $1 / 4$ " cracks) 


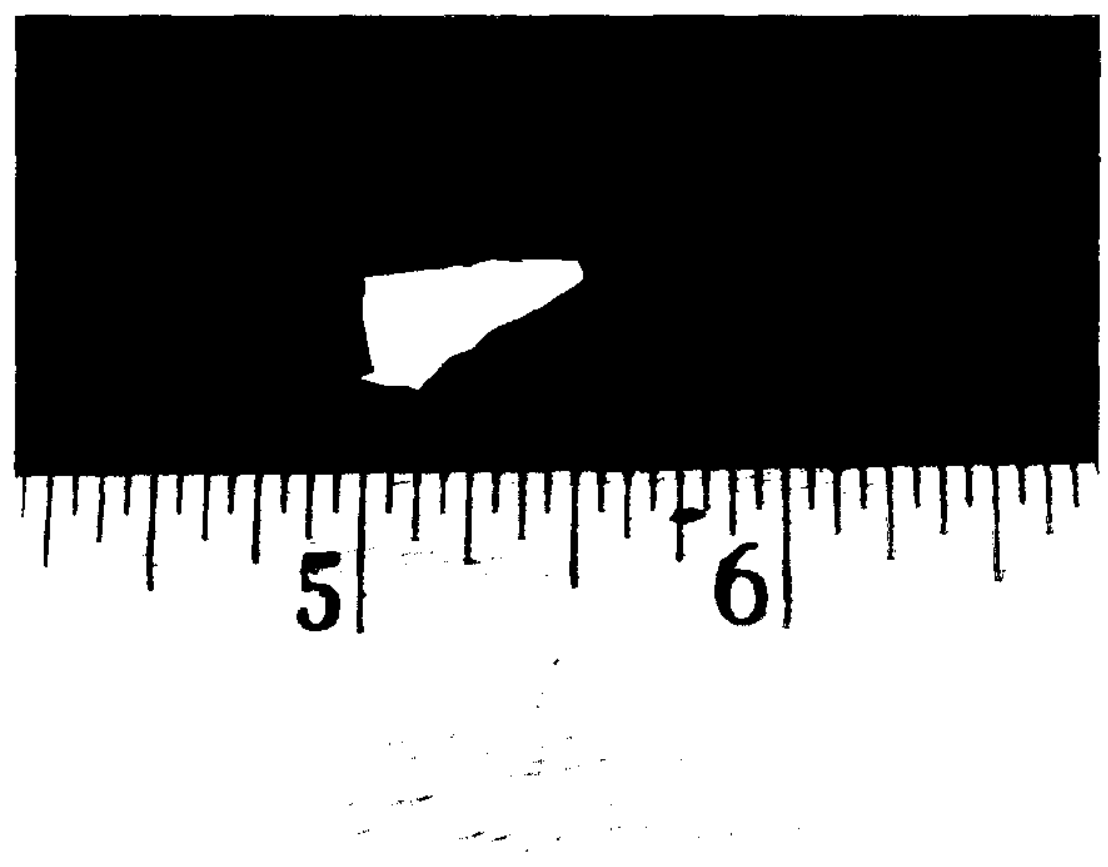

Figure 3-4. As-received chip from Rx spray - header steel location

\subsection{SEM Analysis}

The inorganic zinc primer side of the chips (from the header steel location) was examined under the scanning electron microscope (SEM) to determine particle size and general surface texture and structure. A secondary electron image revealed the relatively rough and non-distinctive surface characteristic of inorganic zinc primer (Figure 3-5). Particles were assumed to be primarily zinc oxide in a silicate matrix, with some possible unreacted or unoxidized zinc metal in regions unexposed during curing and post-failure exposure to the environment. Due to the relatively high reactivity of zinc, however, the majority of exposed metal dust/particles were assumed to have either reacted with the ethyl silicate binder to form either a zinc silicate "polymer" or zinc oxide.

A backscattered electron image of the same area shown in Figure 3-5 is provided in Figure 3-6 to show the relative difference between the two imaging techniques. In the backscattered image, the conductive areas are shown in white with the non-conductive areas being darker. The relevant fact to note from these images is that although the inorganic zinc primer was assumed to be polymerized/oxidized, it was still relatively conductive even in the uncoated condition (uncoated with either gold or carbon typically used for imaging of non-conductive materials).

Secondary electron images of the same general area and features are shown from 500 to $5000 \mathrm{X}$ in figures 3-7 to 3-10, with the majority of zinc oxide particles observed to be less than $20 \mu \mathrm{m}$ in diameter. At the higher magnifications, cleavage planes (splitting of the particulates) were observed. Cleavage of particles may have occurred during coating failure or may be an artifact of the coating curing process. 


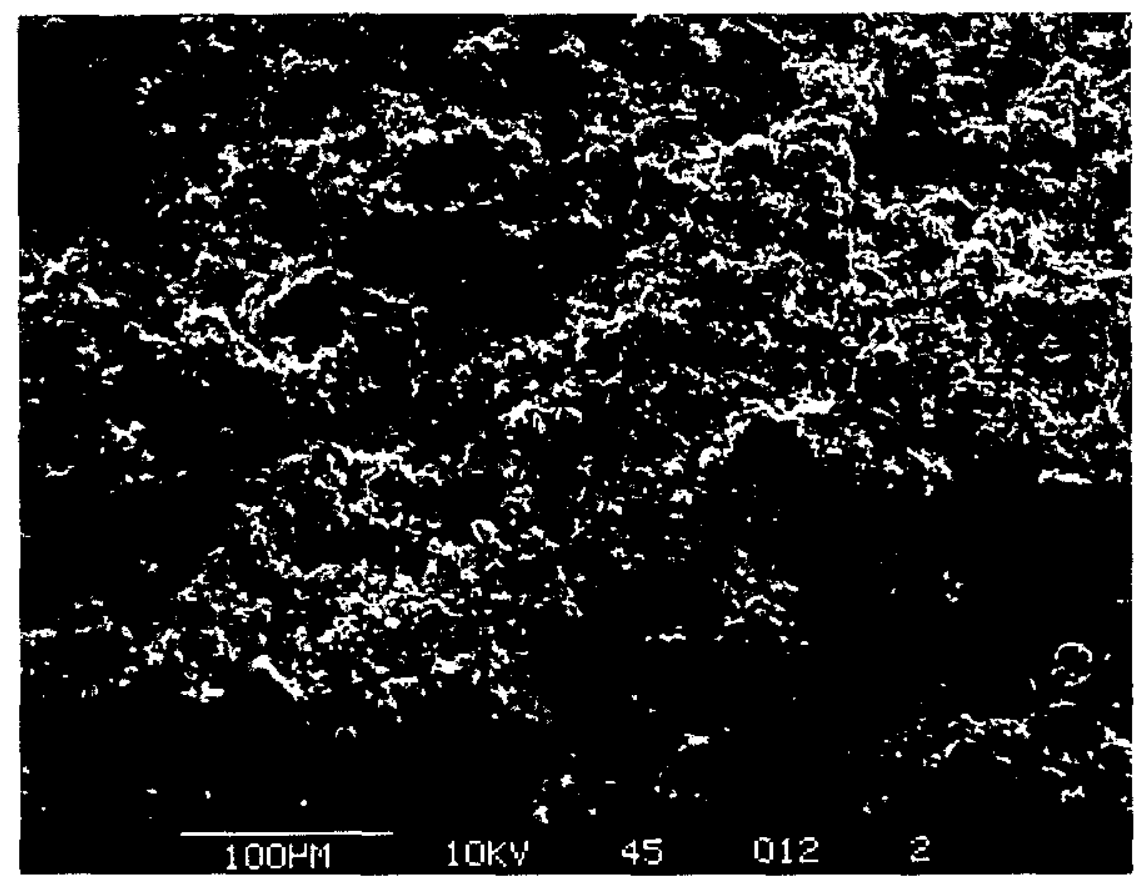

Figure 3-5. Secondary electron (SE) image of inorganic zinc primer - header steel location (200X)

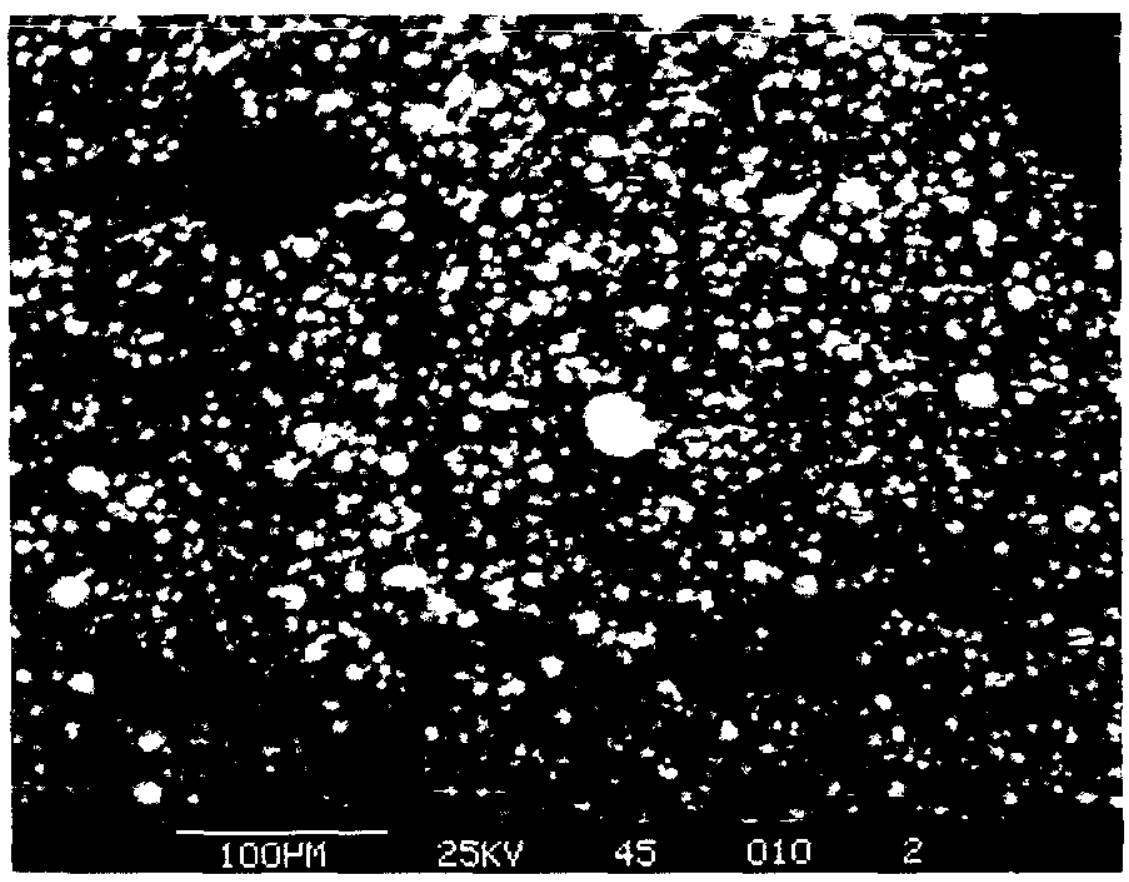

Figure 3-6. Backscattered image of inorganic zinc primer - header steel location (200X) (same area as Figure 3-5) 


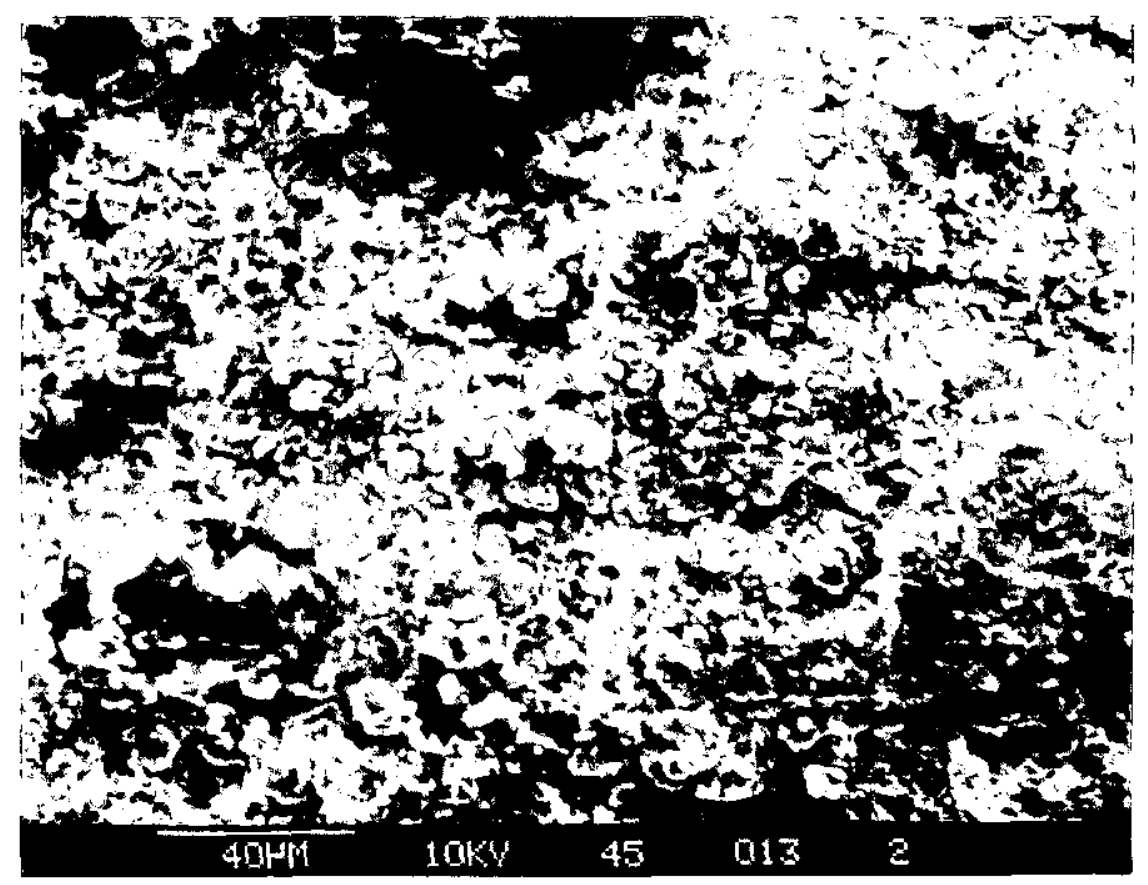

Figure 3-7. Secondary electron image of inorganic zinc primer (500X)

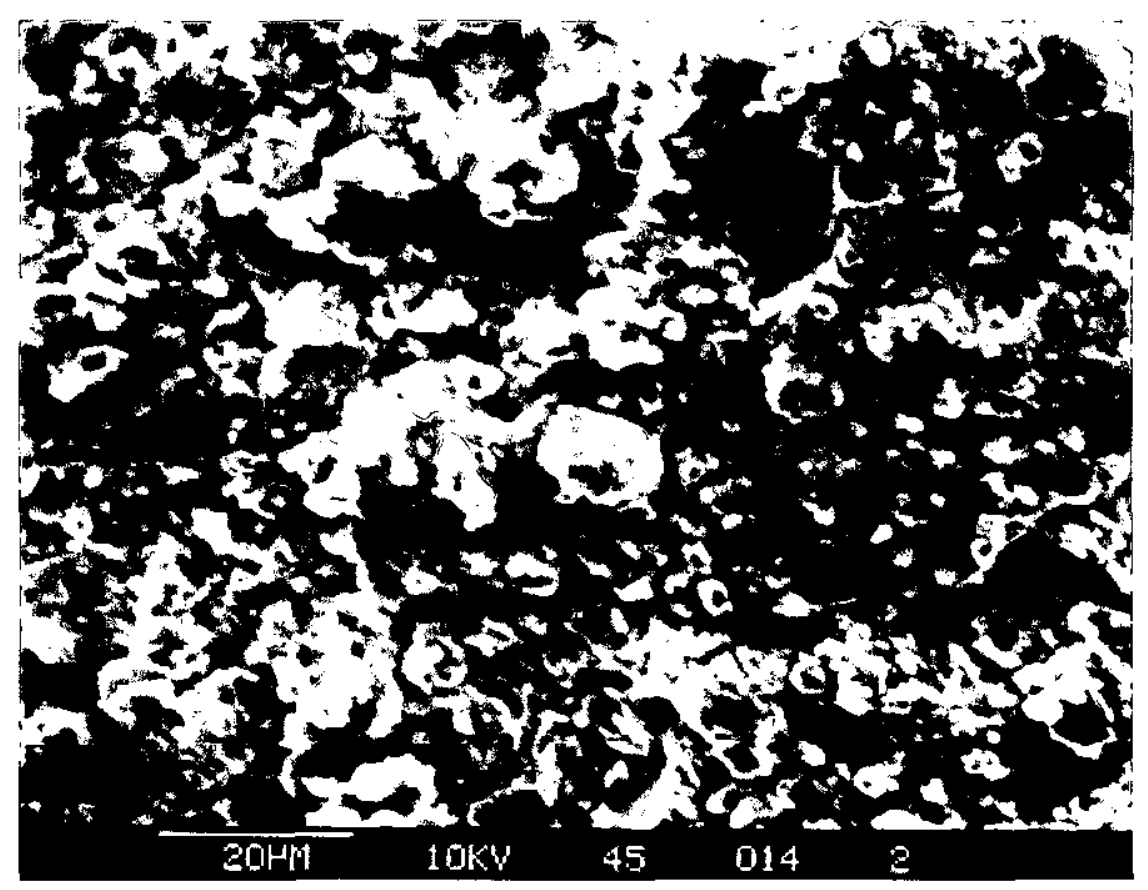

Figure 3-8. Secondary electron image of inorganic zinc primer (1000X) Note size of $\mathrm{Zn} / \mathrm{ZnO}$ particles $(<20 \mu \mathrm{m})$ 


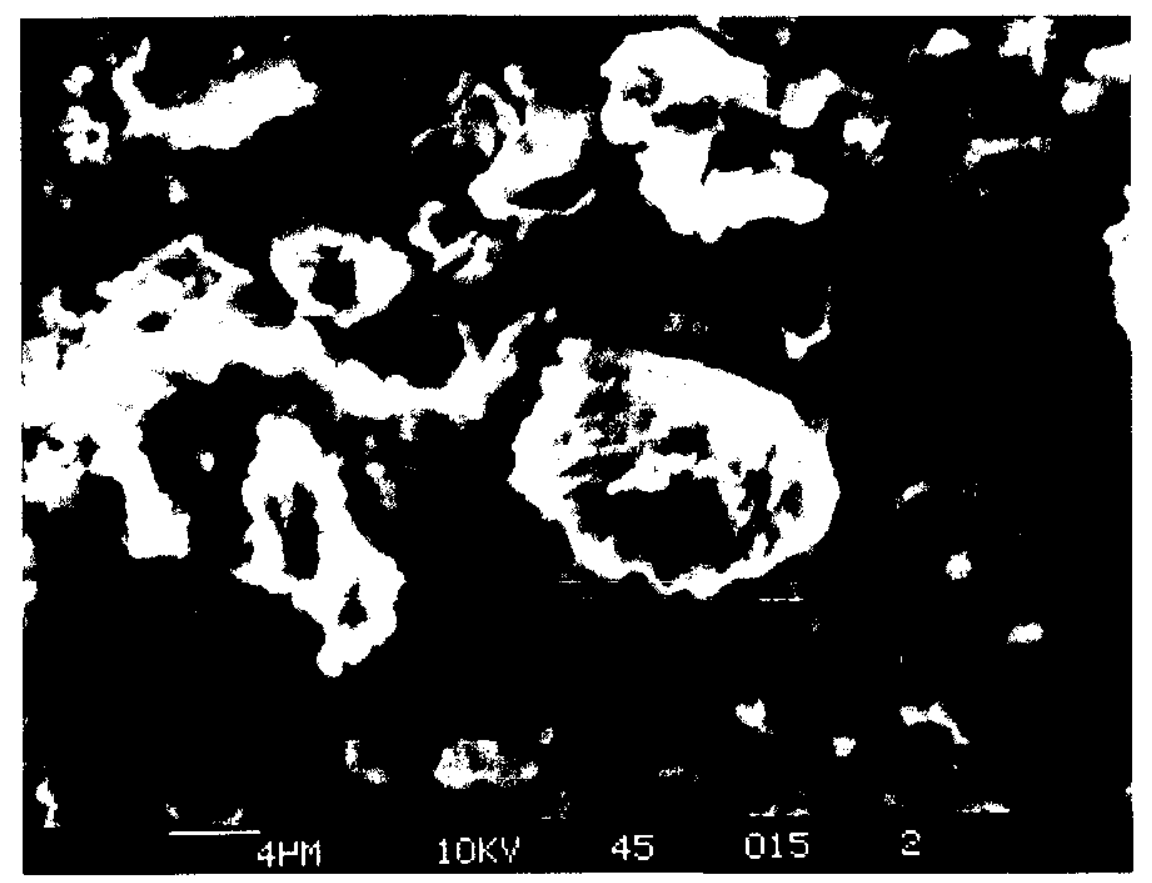

Figure 3-9. Secondary electron image of larger particle (from center of Figure 20), $2500 \mathrm{X}$.

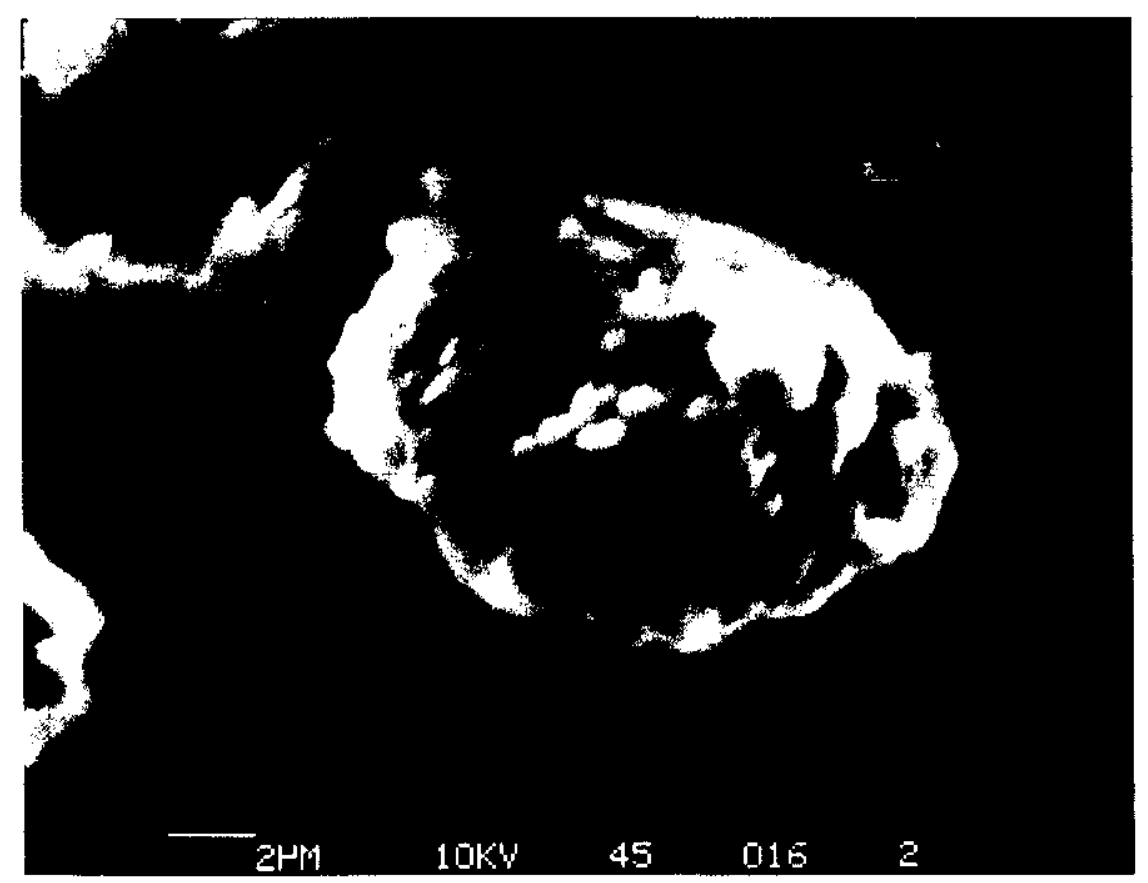

Figure 3-10. Secondary electron image of larger particle, note cleavage plane (loss of clarity at high magnification), $5000 \mathrm{X}$ 


\subsection{Plate Specimens - Plant Number 3}

\subsubsection{D3911 DBA/LOCA - First Test}

An ASTM D3911-95 design basis loss-of-coolant accident test was completed on a coated steel specimen removed from a snubber support base plate from a commercial nuclear power station. The specimen had experienced actual service conditions in containment for approximately 15 years.

The test specimen was approximately $3 \times 5$ inches and was coated on the two main faces with two coats of Mobil/Valspar amine-cured epoxy (78W300). One face had a noticeable number of scratches present in the coating, with the other face relatively clear of scratches. The edges of the specimen were bare steel, the specimen having recently been removed from the plant. These edges were painted at SRTC prior to testing to minimize formation of carbon steel corrosion products, which could interfere with the test chamber spray system. The best-looking face of the specimen was placed so it could be viewed in the video-borescope during the test.

A crack in the coating appeared in the video-borescope image approximately 34.5 hours after the DBA test began, approximately 31.5 hours after decreasing the test chamber pressure to $30 \mathrm{psia}, 250^{\circ} \mathrm{F}$ and beginning the application of water spray. This crack is the left-most crack visible in Figure 4-1. The crack in the coating had been growing for some time prior to becoming visible in the borescope image. It could be seen growing approximately the last inch of its length over the course of approximately 45 minutes, remaining unchanged in the image after that time.

When the specimen was removed from the test chamber, a large chip, approximately 2.75 inches square, was present on the surface of the specimen which was visible in the video-borescope image. The chip was still attached on two edges, but appeared very fragile. No evidence of coating failure was observed on the back face of the specimen.

Figures 4-2 and 4-3 document the appearance and removal of the chip. Figures 4-4 and 4-5 illustrate the condition of the surface of the steel plate beneath the failed chip. The surface preparation in this area does not appear to have been adequate to ensure adhesion of the coating during the DBA test. The poor surface preparation in this area was probably an anomalous oversight, caused by the presence of identification markings scribed into the plate surface in the area of failure. Tests were performed on the coating remaining on the test specimen to determine the adequacy of the coating adhesion in those areas. Their results are reported at the end of this section.

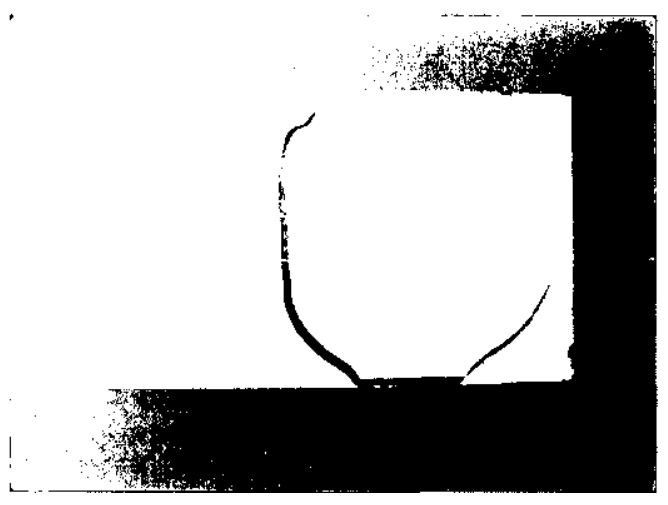

Figure 4-1. Overall view of snubber support base plate specimen as it appeared after DBA testing. 


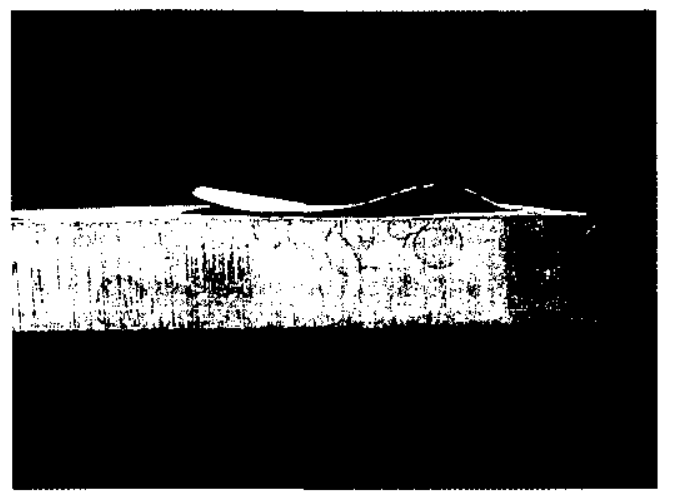

Figure 4-2. Side-view of the test specimen illustrating the extent of coating delamination.

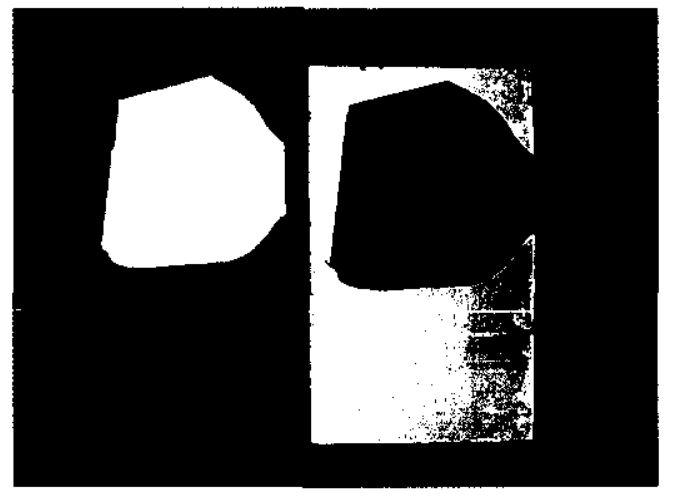

Figure 4-3. Overall view of the test specimen after removal of the failed chip. Note: The chip was removed approximately along the bond/non-bond interface.

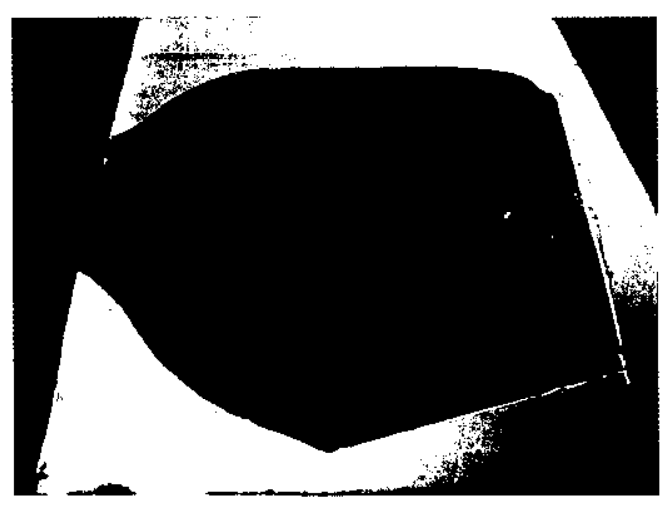

Figure 4-4. Close-up view of the test specimen revealing identification markings in the steel plate surface beneath the failed chip. Note: The surface in this area appeared smooth, with minor surface scratches similar to what might be expected from wire brushing. 


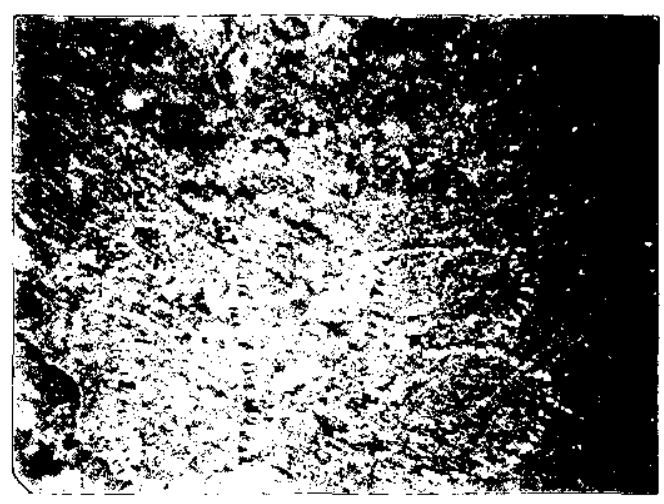

Figure 4-5. Close-up view of the surface of the steel plate beneath the failed chip illustrating the smooth, lightly brushed appearance. Note the presence of coating remnants in the marking indentations. (Magnification about 10X)

\subsubsection{D3911 DBA/LOCA - Second Test with partial immersion}

A second snubber support base plate specimen was sectioned, and half of it was irradiation-aged to $1 \times 10^{9}$ rads at $1 \times 10^{6} \mathrm{rads} /$ hour and $120^{\circ} \mathrm{F}$, in accordance with ASTM D4082-95. After irradiation, the non-aged and the irradiation-aged portions were further sectioned to provide specimens for use in DBA/LOCA and immersion testing.

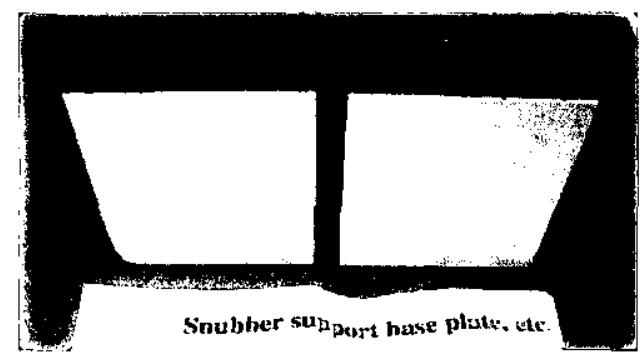

Figure 4-6. Overall view of the coated steel specimen provided from an operating nuclear power plant. The specimen was coated on the two main surfaces with two coats of Mobil 78-W-300.

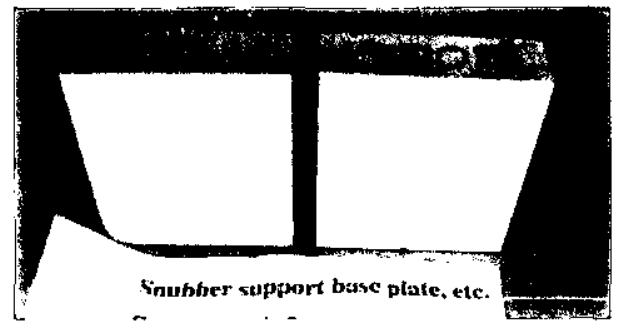

Figure 4-7. Overall view of the snubber support specimen following irradiation aging of the left half to $1 \times 10^{\circ} \mathrm{rads}$ at $1 \times 10^{6} \mathrm{rad} / \mathrm{hr}$ and $120^{\circ} \mathrm{F}$ in the SRTC gamma cell.

Design-basis accident/LOCA testing was performed on the specimens according to ASTM D3911-95, except the bottoms of each specimen were allowed to become immersed during the spray-cooling portion of the test. During testing, the irradiation-aged specimen exhibited extensive blistering of the coating, including the intra-coating delamination of a significant portion of one face. The non-irradiated specimen exhibited only minor, localized surface blistering. No significant debris was released from the specimens; however, no effort was made to collect debris particles that may have been released. 


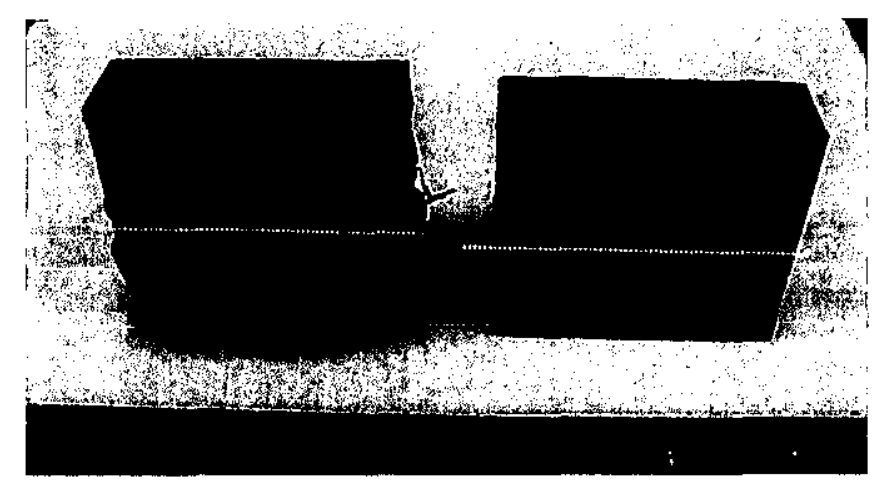

Figure 4-8. Overall view of the snubber support plate specimens following DBA/LOCA testing. The irradiated specimen (left) exhibited delamination and blistering of all of the coated surfaces. The non-aged specimen exhibited minor blistering. The dotted lines indicate the approximate immersion level. Note: The yellow paint present on the cut surfaces of the specimens was applied by SRTC to help control the formation of rust during the DBA/LOCA testing.

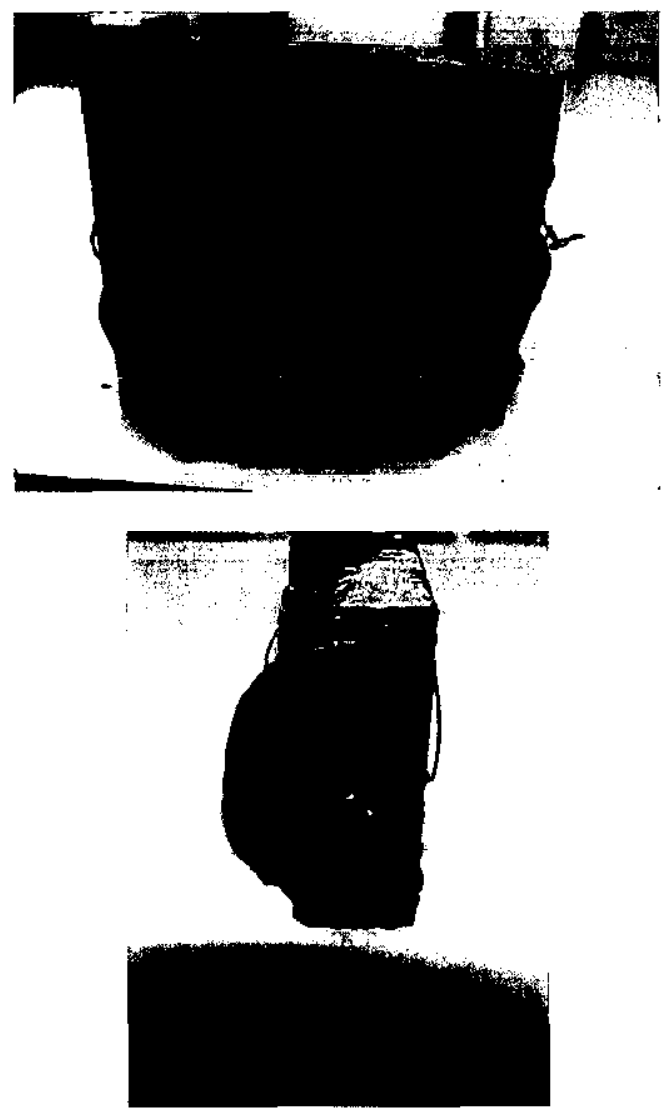

Figure 4-9. Front and side views of the irradiation-aged specimen illustrating the extensive blistering present following DBA/LOCA testing. Note: The wire was used to secure a thermocouple to the specimen front surface during testing.

Examination of the irradiation-aged specimen revealed the thickness of the coating in the delaminated chip to be about 0.012 inch, considerably thicker than the $0.001-0.002$ inch blisters which developed during testing of similar, irradiation-aged coatings, which were freshly applied. This suggests the exposure to the plant environment may have made the coating more susceptible to damage during irradiation-aging. As there is evidence coating damage results from a combined effect of irradiation and oxygen permeation, this 
difference in depth of damage can, perhaps, be explained as a difference in the depth of oxidation of the coating, which occurred prior to irradiation.

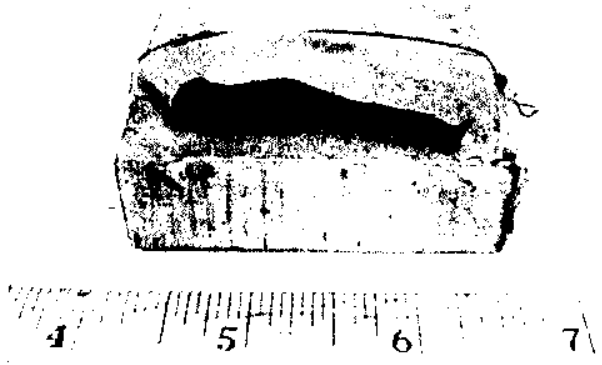

Figure 4-10. Bottom view of the irradiation-aged specimen ilustrating the delamination that occurred in the immersed portion of the specimen during DBA/LOCA testing. The coating was split intra-coating (i.e., a portion of the coating remained on the steel substrate).

\section{\$.1.3 Immersion Test}

Portions of the aged and non-aged coating specimens were immersed in room temperature water, which was then heated to $200^{\circ} \mathrm{F}$ (Figure 4-11). As the water was heated, gas bubbles appeared on the coated surfaces of the irradiated specimen, accompanied by the formation of blisters in the coating as the temperature approached $200^{\circ} \mathrm{F}$ (Figure 4-12).

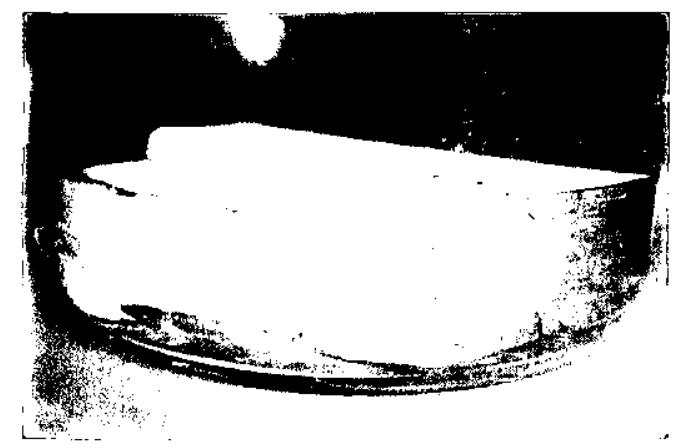

Figure 4-11. Overall view of the irradiation-aged (yellow, front) and non-aged (white, back) specimens in room temperature water at the beginning of immersion testing.

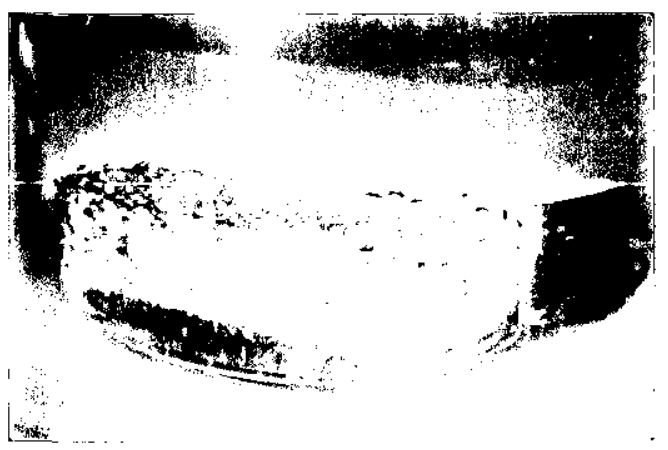

Figure 4-12. Overall view of the aged and non-aged specimens after immersion for approximately 2 hours in $200^{\circ} \mathrm{F}$ water. Note the formation of gas bubbles and blisters on the coated surfaces of the irradiation-aged specimen. 
When the specimens were removed from the immersion test bath, the entire surface of the irradiation-aged specimen exhibited blistering of the coating, whereas the non-irradiated specimen was unaffected (Figure 4-13). The coating did not "fail", according to the failure criteria in ASTM D3911-95, however, no effort was made to collect debris particles that may have been released from the coating.

Microscopic examination of the irradiated specimen revealed an extensive network of pores and blisters throughout the coating. Measurements of the coating thickness made in broken blisters revealed a delamination depth similar to that seen in the DBA/LOCA testing. As before, a remnant of coating remained on the substrate beneath the blisters (Figure 4-14).

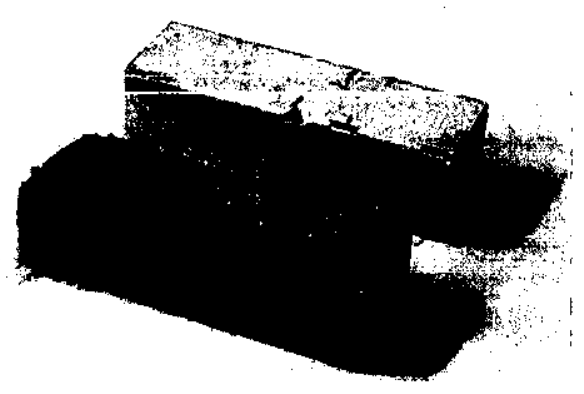

Figure 4-13. Immersion test specimens following removal from the test vessel. No evidence of coating degradation was observed on the non-aged specimen.

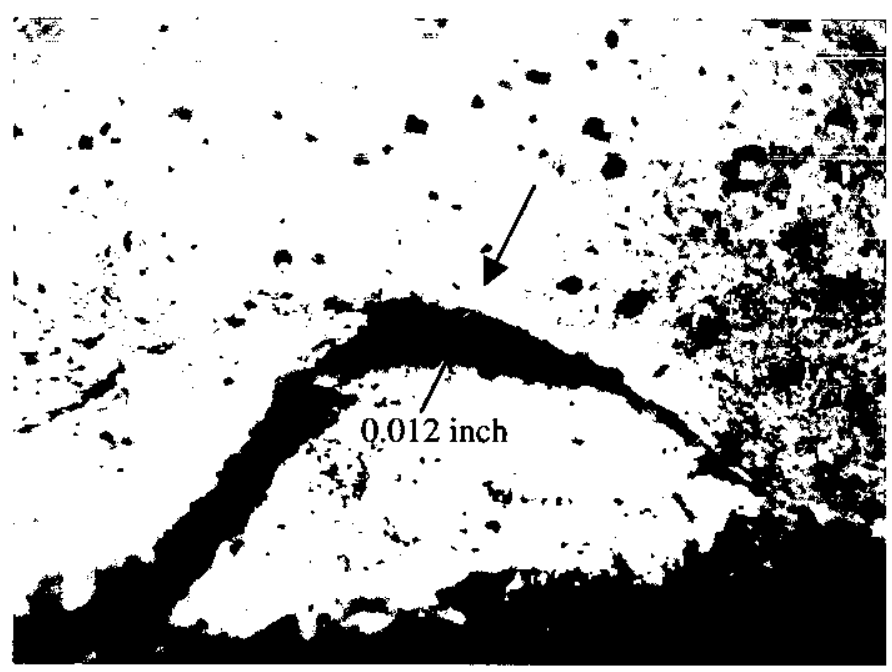

Figure 4-14 Photomicrograph of the surface of the irradiation-aged specimen following immersion testing. The thickness of the broken blister is approximately 0.012 inch - which is consistent with the delamination observed in the DBA/LOCA test. Note, also, the presence of minor blisters and pores in the surface of the coating. Magnification approximately 10x.

\subsubsection{Adhesion Pull Test Results}

Adhesion pull tests were performed on an as-received snubber plate and on a plate that had been DBALOCA-tested. Adhesion pull tests performed on the DBA-LOCA tested plate described in section 4.1.1, on the intact coating next to the removed chip, produced a strength result (load at failure divided by puller area) of 1290 psi in one test and an exceptional value of 3000 psi in a second test. It may be assumed that 
the adhesion strength under the failed chip was zero. These results indicate that the quality of the coating/substrate bond can vary substantially over only a very small sample area.

Figure 4-15 shows the load-extension results from an as-received plate in the dry condition. The highest strength was $1970 \mathrm{psi}$ at $100^{\circ} \mathrm{F}$, in which test failure, or separation of the puller from the substrate, occurred at what appeared to be the topcoat/primer coat interface. In the lower strength failures at $100^{\circ} \mathrm{F}$, failure occurred at the topcoat/primer interface as well as at the primer coat/substrate interface. In the instances of separation at the substrate, there appeared to be spots of rust on the steel substrate, which probably accounts for the lower strengths. The relatively lower strength and more ductile failure observed in the $200^{\circ} \mathrm{F}$ test compared with the $100^{\circ} \mathrm{F}$ tests are consistent with observations in the epoxy phenolic/inorganic zinc coating on steel (the SRTC System I coating).

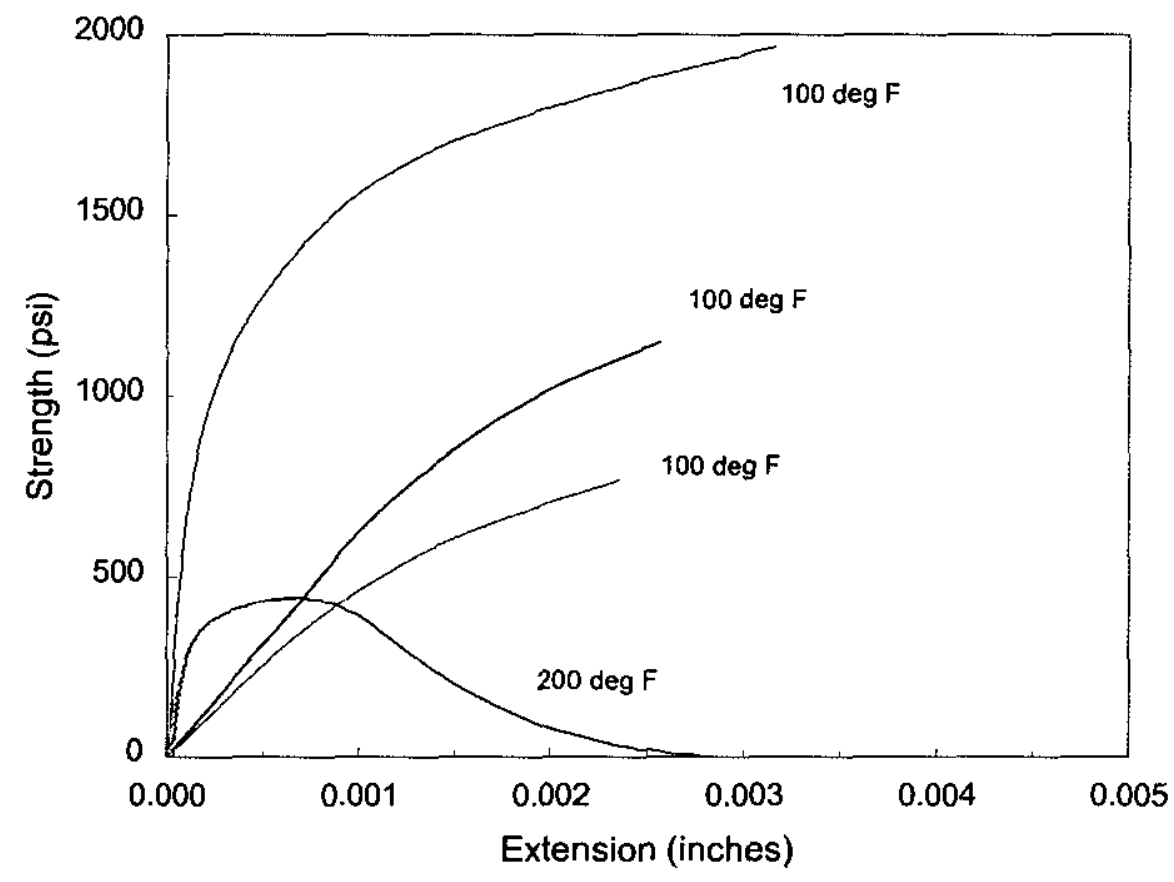

Figure 4-15. Adhesion pull test results from the as-received snubber plate at $100^{\circ} \mathrm{F}$ and $200^{\circ} \mathrm{F}$ in the dry condition 


\subsection{Handrail Specimen - Plant Number 3}

\subsubsection{D3911 DBA/LOCA}

A DBA-LOCA test was performed, according to ASTM D3911-95, on a section of coated steel handrail provided by a commercial nuclear generating station. The coating system consisted of two coats of Mobil/Valspar amine-cured epoxy (78W300). The specimen was divided, with half tested in the asreceived condition, and half tested after irradiation-aging to $1 \times 10^{9} \mathrm{rad}$ at $1 \times 10^{6} \mathrm{rad} / \mathrm{hour}$ at $120^{\circ} \mathrm{F}$ (Figure 4-16).

The coating did not fail, according to the acceptance criteria of the ASTM specification (Figures 4-17 and 4-18). However, under microscopic examination, there was evidence of failure of the coating in the irradiated specimen, similar to what has been observed in other iradiated specimens - by release of fine particles (Figure 4-19).
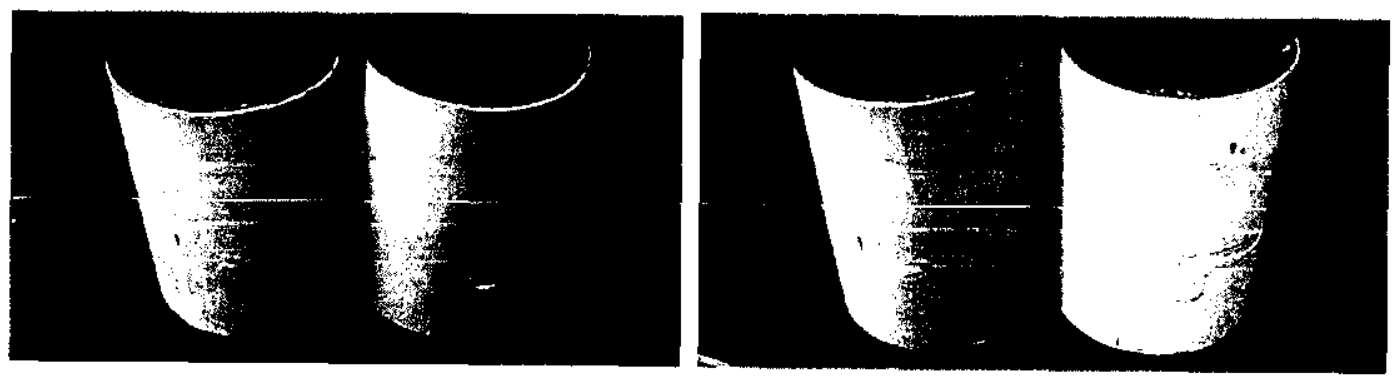

Figure 4-16. Overall views of the handrail specimen as it appeared as-received and after dividing in half (left), and after irradiation-aging of half of the specimen (right).

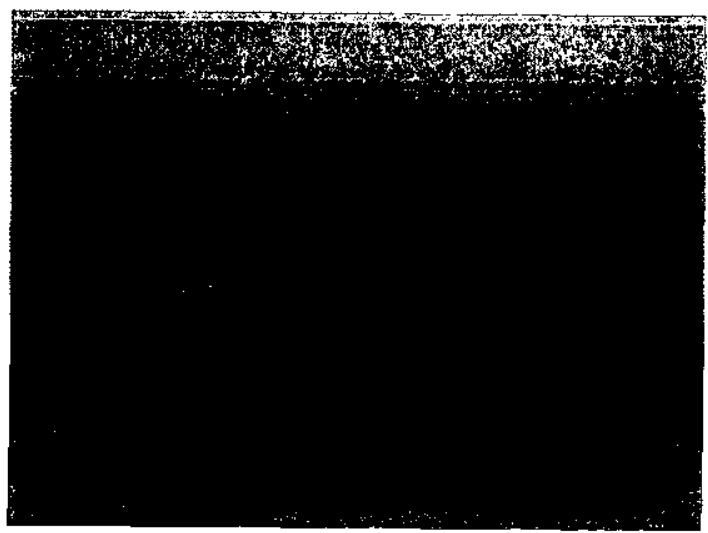

Figure 4-17. Overall view of the handrail specimens, after DBA-LOCA testing. The as-received specimen is on the left; the irradiation-aged specimen is on the right. 
WSRC-TR-2001-00163

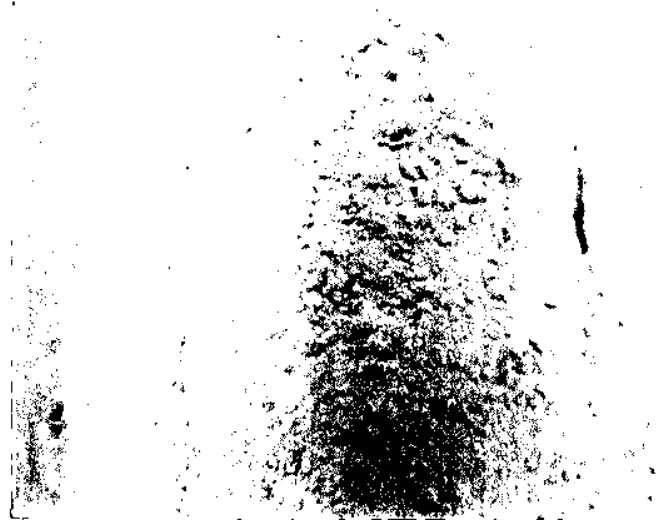

Figure 4-18. Macroscopic view of the surface of the irradiation-aged specimen, revealing the presence of intact blisters.

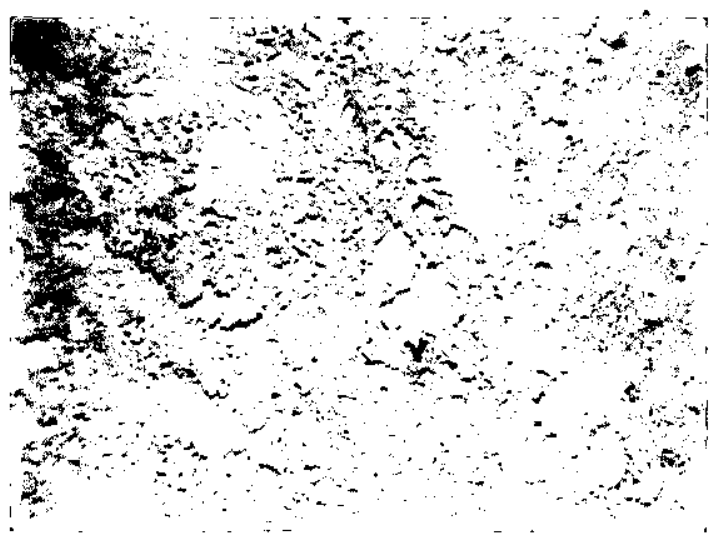

Figure 4-19. Microscopic view of the surface of the irradiation-aged iandrail specimen, following DBA-LOCA testing. Magnification is approximately $7 x$.

\subsubsection{Immersion Testing}

The following series of photographs, the first three taken from a time-lapse video, illustrates the immersion test performance of portions of the handrail specimen. The specimen on the left is in the as-received condition, whereas the specimen on the right has been irradiated to $1 \times 10^{9} \mathrm{rad}$ at $1 \times 10^{6} \mathrm{rad} /$ hour and $120^{\circ}$ $\mathrm{F}$ according to ASTM D4082-95.

The first image (Figure 4-20) illustrates the condition of the specimens immediately after immersing them into water, preheated to $200^{\circ} \mathrm{F}$. The next image (Figure 4-21) illustrates the appearance of the specimens after 10 minutes. Note the formation of a uniform layer of bubbles and blisters on the surface of the irradiated specimen. The rapid formation and release of bubbles is consistent with the hypothesis of gas formation within an epoxy topcoat during the irradiation of the specimen. 


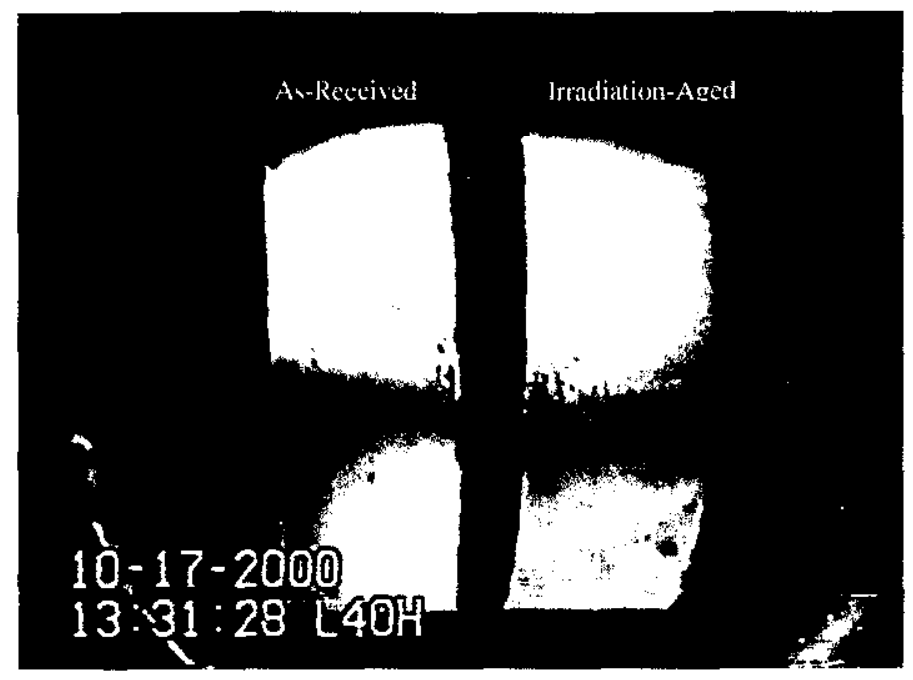

Figure 4-20. Handrail specimens immediately after immersion in water preheated to $200^{\circ} \mathrm{F}$.

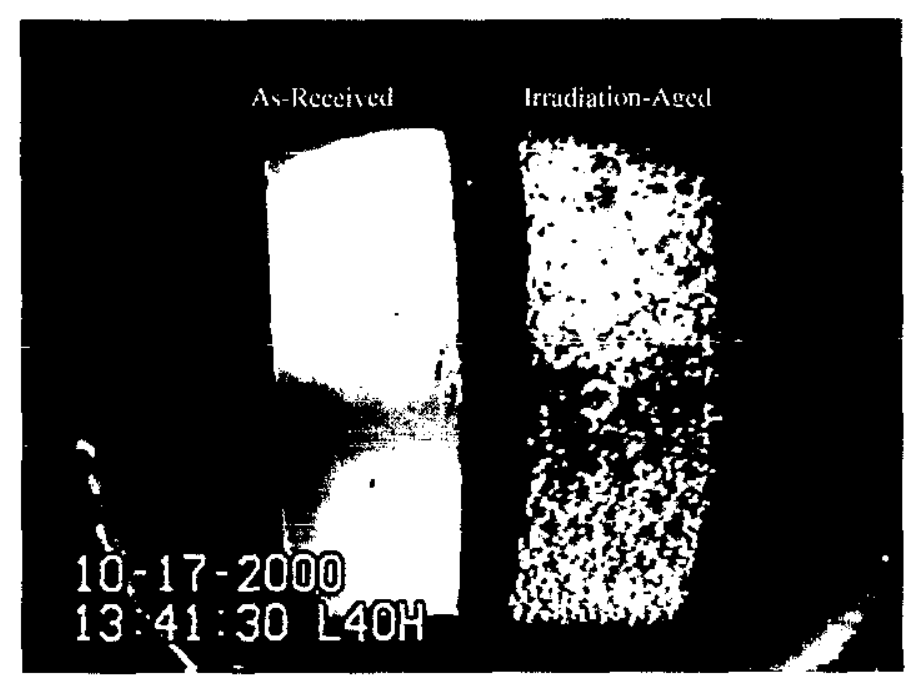

Figure 4-21. Handrail specimens 10 minutes after immersion in water preheated to $200^{\circ} \mathrm{F}$.

The addition of heat was terminated after approximately 2.5 hours and the specimens were allowed to cool under water. Figure 4-22 shows the appearance of the specimens after cooling for approximately 1.5 hours. 


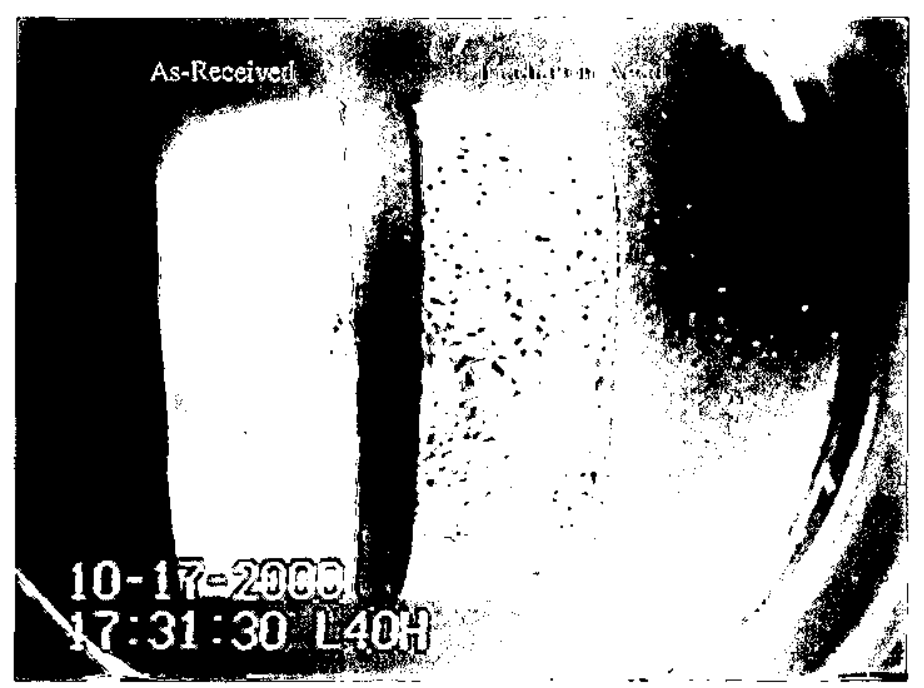

Figure 4-22. Handrail specimens at the end of the immersion tests.

The last image (Figure 4-23) shows the appearance of the irradiation-aged specimen after removal from the immersion test. Note the extensive surface blistering, with rupture or collapse of most of the blisters. The blisters do not penetrate to the substrate, i.e., they are confined within the outermost layer of the topcoat, as has been observed in immersion testing of other irradiated epoxy coatings.

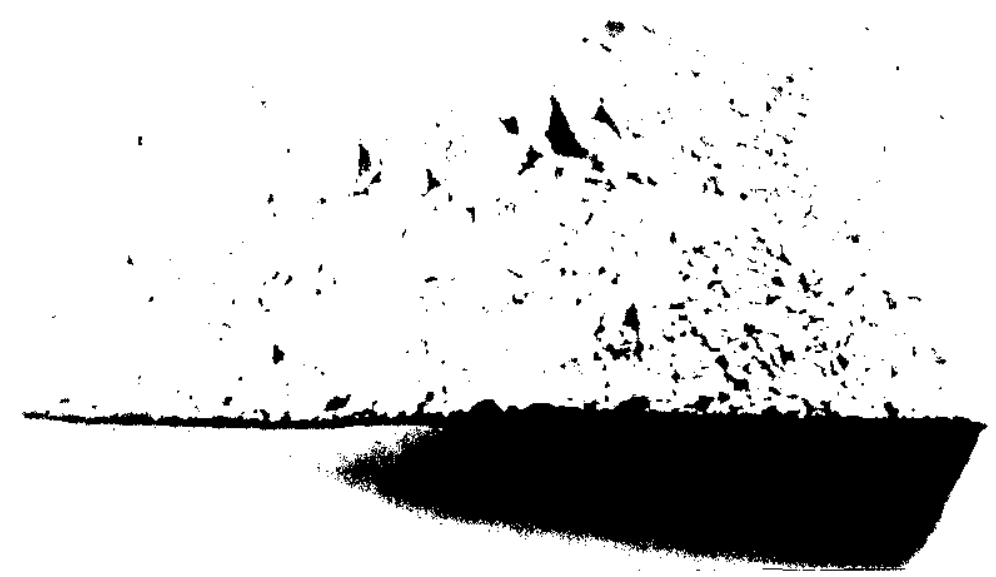

Figure 4-23. Irradiation-aged handrail specimen after removal from the water immersion test. 


\subsection{Contaminated Plate Specimens - Plant Number 4}

\subsection{Immersion Testing}

A water immersion test was performed on a coated steel plate specimen removed from an operating commercial nuclear power plant after more than 20 years of service. The coating system consisted of a Carbozinc ${ }^{\boxplus} 11$ primer with a Phenoline ${ }^{\otimes} 305$ topcoat. The specimen had slight surface contamination, and was tested in the as-received condition only, i.e., no additional irradiation of the test specimen was performed (Figure 5-2).

In the immersion testing, the specimen was placed into room temperature water, which was then heated to $200^{\circ} \mathrm{F}$ and held for approximately 24 hours. No evidence of coating failure was observed (Figure 5-3).

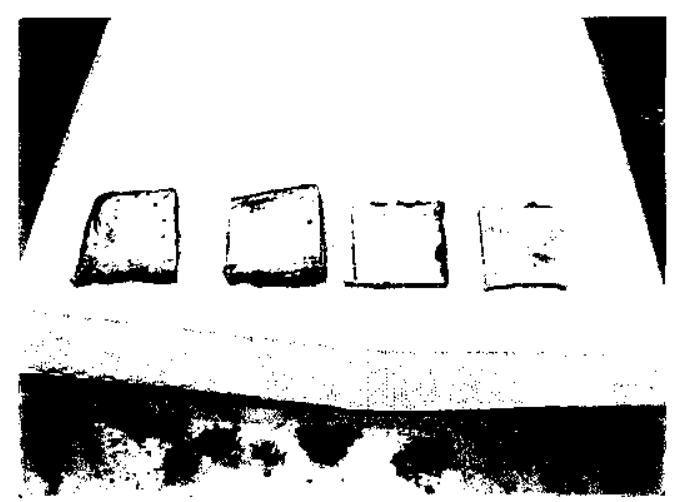

Figure 5-1 Overall view of coated steel plate specimens. The specimens are approximately 2 inches square, each, and were saw-cut from a plate which appeared to have been removed from service with a cutting torch.

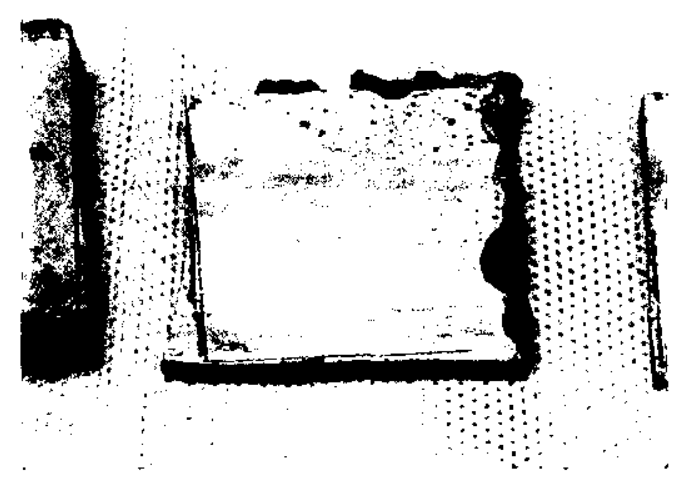

Figure 5-2 Overall view of one of the coated plate specimens as it appeared prior to immersion testing. 


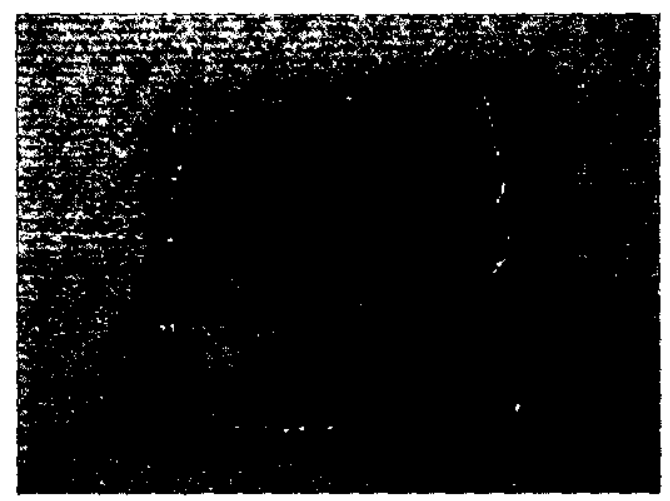

Figure 5-3 Overall view of the coated plate specimen as it appeared after immersion in $200^{\circ} \mathrm{F}$ water for approximately 24 hours. Only minor corrosion of the saw-cut edges of the specimen was observed. 


\subsection{Conclusions}

The examination and testing of failed coating specimens, obtained from two different plants, indicated the coatings failed as a consequence of improper application, rather than as a result of time-in-service or environmental conditions. However, SRTC was not able to obtain intact coating specimens from these same plants to confirm this conclusion.

The DBA/LOCA testing performed by SRTC on plant-aged plate and handrail specimens from two different plants revealed acceptable coating performance, in the as-received condition. The coatings did not fail, according to the acceptance criteria of ASTM D3911, and remained well-adhered, except in a portion of one plate which had not received adequate surface preparation prior to coating application. However, when specimens of coatings from one of these plants were tested following the accelerated irrađiation-aging specified in ASTM D4082, extensive blistering and intra-coating delamination was observed. As irradiation-aged specimens of this coating (Mobil/Valspar 78W300) would have passed these same test conditions during initial qualification, failure of the plant-aged specimens indicates the coating has experienced a degradation of properties, due to time-in-service and/or the environmental conditions to which it has been exposed.

The SRTC coatings performance evaluation program has previously reported a coating failure mechanism which occurs when irradiation-aged coatings are immersed in hot $\left(200^{\circ} \mathrm{F}\right)$ water. (See References in Section 1). Under these test conditions, recently-applied coatings, which were irradiation-aged according to ASTM D4082, blistered and failed, releasing coating debris from the outermost layer of the topcoat. The coating failures observed in these recently-applied coatings have been confined to a depth in the topcoat of approximately 0.002 inch. Immersion testing of plant-aged specimens of Mobil/Valspar 78W300 following accelerated irradiation-aging revealed a similar coating failure, except coating failure extended to a depth of approximately 0.012 inch. This greater depth of damage could be further evidence of coating degradation resulting from time and service conditions.

It must be made explicitly clear that only plant-aged specimens of Mobil/Valspar $78 \mathrm{~W} 300$ were tested following accelerated irradiation-aging. Therefore, no conclusions can be drawn regarding the performance of other plant-aged coatings, when subjected to similar irradiation-aging and test conditions. As a consequence of the limited number of plant-aged specimens made available for testing, no definitive conclusions can be made regarding the effects of time, temperature, irradiation dose-rate, and/or total irradiation dose on the performance of service-aged coating systems. 


\section{Westinghouse Savannah River Company Document Approval Sheet}

\section{Title}

Degradation and Failure Characteristics of NPP Containment Protective Coating Systems Primary Author/Contact (Must be WSRC)

Robert L. Sindelar Organization Code Location

773-41A Room 136

Phone No.

Organization (No Abbreviations) 725-5298

Savannah River Technology Center / Materials Technology Section

L2530

Other Authors

M.E. Dupont, N.C. lyer, P.S. Lam, T.E. Skidmore, F. R. Utsch, P.E.

Has an invention disclosure, patent application or copyright application been submitted related to this information?

Disclosure No. (If Known)

If no, do you intend to submit one?

Information Product Description

$\bigotimes$ TechnicalReport

$\square$ Semiannual $\square$ Annual $\square$ Final $\square$ Topical $\bigotimes$ Other Interim

$\square$ Administrative Report

$\square$ Semiannual $\square$ Annual $\square$ final $\square$ Topical $\square$ other

\section{$\square$ Videotape/Multimedia}

$\square$ External Web Page URL

$\square$ Brochure/Booklet

$\square$ Procedure/User Guide

$\square$ Drawing

$\square$ Software Package (for sypmissign to ESTSC)

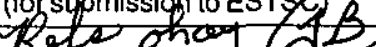

Key Words (list 3)

\begin{tabular}{|l|l|}
\hline $\begin{array}{l}\text { DocumentNo. } \\
\text { WSRC-TR-2001-00163 }\end{array}$ \\
\hline Requested Approval Date \\
$4 / 15 / 01$ \\
\hline $\begin{array}{l}\text { Position } \\
\text { Sr. Fellow Engineer }\end{array}$ & T76er ID \\
\hline
\end{tabular}

coating,DBA, LOCA,ETC,paint, failure, modeling

$\square$ Yes $\bigotimes$ No If yes, date submitted

Title

References $\triangle$ Approved for ReleasefPublely Available $\square$ Included as Attachment(s) $\square$ Routing Concurrently $\square$ Other

$I$ understand that for the information in this material to be given external distribution, approvals by both WSRC and, as appropriate, DOE-SR are required. Distribution (verbally or published) must be in accordance with policies set forth in WSRC managernent requirements and procedures (MRP 3.25) and in DOE-SR orders, and the content of the external djstribution must be limited to that actually approved.

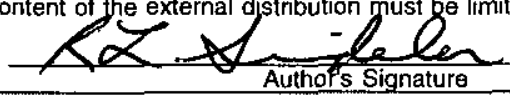

\section{Approvals by Author's Organization}

\begin{tabular}{l|l|l|l|l|l} 
Classification \\
Unclassified
\end{tabular}
Unlimited (release to public)
$\square$ Site Use Only
$\square$ Corporate/University Partner

Limited (see explanation)

$I$ understand and have considered whether any potential intellectual property rights (patents, copyrights, etc., in accordance with MP 1.09 and MRP 1.07) or any contractural barriers (CRADAs, Work for Others, etc.) may be involved before authorizing that this document be proposed for public release. If any concerns were identified, these have been discussed and resolved with Gengral Gunggl.

$$
\text { Naytraj C. lyer }
$$

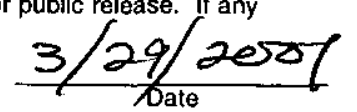

Classification Informaton (To be Completed by WSRC Classification Office)

Classification (Check One for Each)

$\begin{array}{lllll}\text { Overall } & \square \mathrm{S} & \square \mathrm{C} & \square \mathrm{UCN} & \square \mathrm{U} \\ \text { Abstract } & \square \mathrm{s} & \square \mathrm{C} & \square \mathrm{UCN} & \square \mathrm{U} \\ \text { Title } & \square \mathrm{s} & \square \mathrm{C} & \square \mathrm{UCN} & \square \mathrm{U}\end{array}$

WSRC Classification Officer's Name (Print)

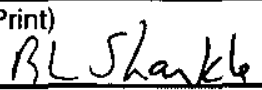

$\square$ OPSEC Review

Classification Guide Topics

\section{wSRC Classifjcgtion Office/s Signature}

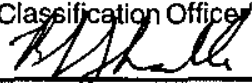

Export Control Review (To be Completed by Export Control Reviewing Official)

Export Control Related $\square$ Yes $\square$ No

Export Control Reviewer's Name (Print) $/\{L S h a, k l$
Export Contrg/Reyigwer's Signature

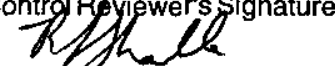

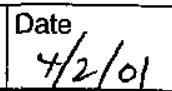

\section{STI Program Use Only}

OSTI Subj. Category No. $5 C-36$ 
April 2, 2001

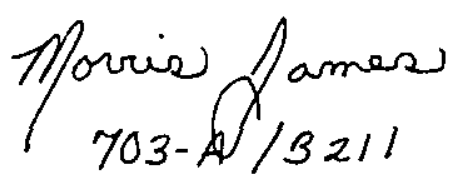

Ms. W. F. Perrin, Technical Information Officer

U. S. Department of Energy - Savannah River Operations Office

Dear Ms. Perrin:

The attached document is submitted for classification and technical approvals for the purpose of external release. Please complete Part II of this letter and return the letter to the undersigned by 4/12/2001. The document has been reviewed for classification and export control by a WSRC Classification staff member and has been determined to be Unclassified.

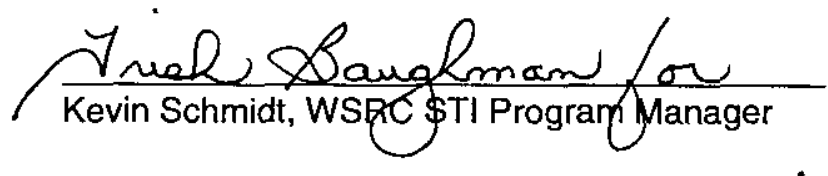

\section{DETAILS OF REQUEST FOR RELEASE}

Document Number: WSRC-TR-2001-00163

Author's Name: R. L. Sindelar

Location: $773-41 \mathrm{~A}, \mathrm{Rm} 136$

Phone 5-5298

Department: Savannah River Technology Center

Document Titie: Degradation and Failure Characteristics of NPP Containment Protective Coating Systems

Presentation/Publication:

Meeting/Joumal:

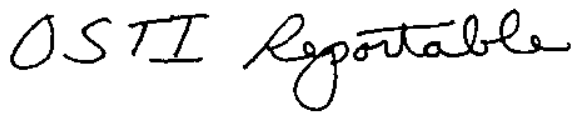

\section{Location: $N / A$}

II. DOE-SR ACTION

Date Received by TIO.

$4+2 / 2001$

X] Approved for Release

$\square$ Approved Upon Completion of Changes

Approved with Remarks

Not Approved

Revise and Resubmit to DOE-SR

Remarks:

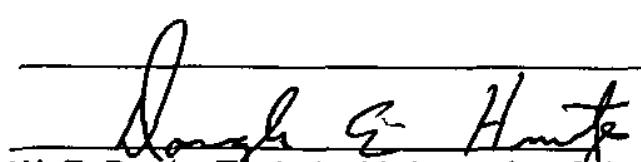

W. F. Perrin, Technical Information Officer, DOE-SR

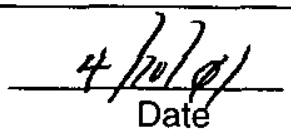


RECORD STATUS (select one):

X...New ......Revised Data ..... Zevised STI Product

Part I: STI PRODUCT DESCRIPTION

A. STI PRODUCT TYPE (select one)

X.. 1. Technical Report
a. Type: $\square$ Topica
Semiannual
Annual $\bigotimes$ Final
Other (specify)
b. Reporting Period $(\mathrm{mm} / \mathrm{dd} / \mathrm{y} y \mathrm{y} y$,
thru

.... 2. Conference
a. Product Type: ...... Conference Proceedings ...
b. Conference Information (title, location, dates)

.... 3. Software Manual ( The actual software package should be made available simultaneously. Follow instructions provided with ESTSC $F 1$ and ESTSC F 2.)

4. Journal Article
a. Type: $\quad \underline{X}$ Announcement citation only
- Preprint
Postprint
b. Journal Name
c. Volume
d. Issue
e. Serial identifier (e.g., ISSN or CODEN)

..... 5. S\&T Accomplishment Report

.... 6. Book

.... 7. Patent Application
a. Date Filed $(\mathrm{mm} / \mathrm{dd} / \mathrm{y} y \mathrm{yy})$
b. Date Priority $(\mathrm{mm} / \mathrm{dd} / \mathrm{y} y \mathrm{y})$
c. Patent Assignee

..... 8. Thesis/Dissertation

B. STI PRODUCT TITLE . Degradation.and.Failure.Characteristics.of..NP.P..Containment.Protective.Coating.Systems C. AUTHOR(s)
E-mail Address $(\theta s)$ :

D. STI PRODUCT IDENTIFIER
1. Report Number(s) WSRC-TR-2001-00163
2. DOE Contract Number(s) _RE-AC09-96SR18500
3. R\&D Project ID(s)
4. Other Identifying Number(s)

E. ORIGINATING RESEARCH ORGANIZATION Savannah River Site

F. DATE OF PUBLICATION ( $\mathrm{mm} / d d / y y y)$ 4/1.0/2001

G. LANGUAGE (if non-English) English

(Grantees and Awardees: Skip to Description/Abstract section at the end of Part I)

H. SPONSORING ORGANIZATION

I. PUBLISHER NAME AND LOCATION (if other than research organization)

Availability (refer requests to (if applicable])

J. SUBJECT CATEGORIES (ist primary one first) $\quad 36$.

Keywords _ Cogating..RBA.LoCA.Paint. Failure.Mo.deling

K. DESCRIPTION/ABSTRACT

Nuclear power plants (NPPs) must ensure that the emergency core cooling system (ECCS) or safety-related

containment spray system (CSS) remains capable of performing its design safety function throughout the life of the plant. This requires ensuring that long-term core cooling can be maintained following a postulated loss-of-coolant accident (LOCA). Adequate safety operation can be impaired if the protective coatings which have been applied to the concrete and steel structures within the primary containment fail, producing transportable debris which could then accumulate on BWR ECCS suction strainers or PWR ECCS sump debris screens located within the containment. This document will present the data collected during the investigation of coating specimens from plants. 


\section{ANNOUNCEMENT OF U. S. DEPARTMENT OF ENERGY (DOE) SCIENTIFIC AND TECHNICAL INFORMATION (STI)}

Part II: STI PRODUCT MEDIA/FORMAT and LOCATION/TRANSMISSION

\section{A. MEDIA/FORMAT INFORMATION}

1. Medium of STI product is: ..... Paper ....... Electronic document ..... Computer medium ..... Audiovisual material

2. Size of STI product

3. File format:

a. If electronic document is posted at site, indicate: $\square$ html $\$ pdfn $\square$ sgml $\square \times \mathrm{xml}$

b. If electronic document is transmitted to OSTI, indicate: $\square$ html $\square$ pdfn $\square$ pdfi $\square$ msword __ TIFFG4 _WP-indicate Version ( 5.0 or greater)

__ MS Word-indicate Version (5.0 or greater) platform/operating system

computer medium or audiovisual material:

a. Quantity/type (specify)

b. Machine compatibility (specify)

c. Sound: platform/operating system Postscript

f. Other information about product format a user needs to know:

\section{B. LOCATION/TRANSMISSION INFORMATION}

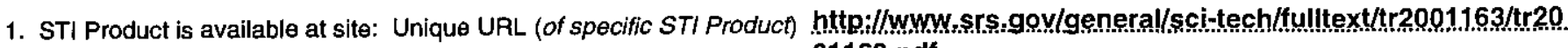

2. STI Product is being transmitted to OSTI: 0.1.63.pdt.

a.__ Electronically via FTP

b. __ Via Mail or shipment (e.g., Federal Express) (Paper products, electronic documents on CD-ROM, diskettes, videocassettes, etc.)

3. Information Product Filename (of transmitted electronic format)

C. ADDITIONAL INFORMATION (concerning media/format or location/transmission; for OSTI internal use only):

(Grantees and Awardees: Skip to Contact section at the end of Part III)

Part III: STI PRODUCT REVIEW? RELEASE INFORMATION

\section{A. ACCESS LIMITATION}

X.... 1. Unlimited Announcement (available to U.S. and non-U.S. public)

....... 2. OpenNet (use OpenNet guidance for below):

a. If additlonal source other than making it available through NTIS:

e. OpenNet Document Type

(1) Accession Number

(2) Document Location

b. Field Office Acronym

c. Declassification date $(\mathrm{mm} / \mathrm{dd} / \mathrm{yyyy})$

d. Declassification Status:

_- Declassified _ Sanitized _ Never classified

3. U.S. Dissemination Only

…... 4. Copyrighted material; Are there any restrictions based on copyright?

f. OpenNet Document Keywords

g. OpenNet Addressee yes no. If yes, list the restrictions
5. Small Business Innovation Research (SBIR) Release date (mm/dd/yyyy)
6. Small Business Technology Transfer (STTR) Release date ( $\mathrm{mm} / \mathrm{dd} / \mathrm{yyyy}$ )
7. Proprietary/Trade Secret
8. Patent Pending

9. Protected data CRADA Other (specify) Release date (mm/dd/yyyy)

10. Official Use Only (OUO)

11. Program-Directed Special Handling (specify)

12. Export Control/TAR/EAR

13. Unclassified Controlled Nuclear Information (UCNI)

14. Classified Classification Level/Categorv of:
a. This form $\mathbf{Y}$.
b. The STI Product Unclasșified

15. Other information relevant to access (specify; for OSTI internal use only))

B. OTHER (information useful to include in published announcement record which is not suited for any other field on this form)

C. CONTACT AND RELEASING OFFICIAL

1.Contact (if appropriate, the organization or site contact to include in published citations who would receive any extemal questions about the content of the STI Product or the research infomation contained therein

Name and/or Position

Kevin Schmidt, Manager STI Program \& Site Support

E-mail Phone (803) 725-2646

Organization Westinghouse Savannah River Company

2. Releasing Official $\mathbf{X}$ I verify that all necessary reviews have been completed (e.g. Patent, Copyright, ECI, UCNI, etc.)

Released by (name) Kevin Schmidt Date $(\mathrm{mm} / d d / y y y y)$ 4/10/2001

E-Maif Phone 